\title{
PARAMETRIC STUDY OF RETENTATE RE-PROCESSING RO DESALINATION UNITS
}

\author{
H. Kotb, E. H. Amer and K. A. Ibrahim \\ Mechanical Power Engineering Department, \\ Faculty of Engineering, Minoufiya University, Shebin El-Kom, Egypt.
}

\begin{abstract}
In this paper several arrangements of two-module feed forward reverse osmosis (RO) systems were investigated. The membrane module was modeled as a tube side feed flow tubular module. A superstructure that incorporates all possible arrangements for two-module feed forward RO systems was developed. This superstructure is used to develop the general mathematical model for the RO system which can be used to simulate any of the module arrangements. Mass materials and energy balances have been applied to each component in the systems. The suggested model has been constructed and solved numerically to obtain a better understanding of characteristics and behavior of modules arrangement. This paper also aims to investigate how external forces such as feed specifications, utility and product costs affect the performance and optimal design of RO systems. The effect of the following parameters on unit performance is investigated such as; feed specifications (flow rate and concentration), operating conditions (feed pressure and temperature) and Membrane dimensions (length and diameter).
\end{abstract}

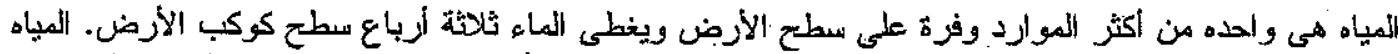

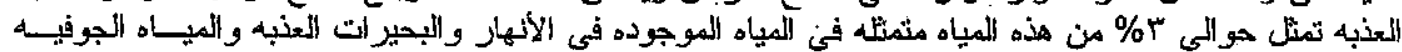

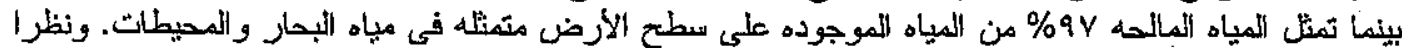

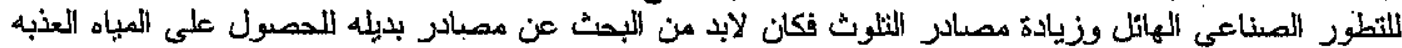

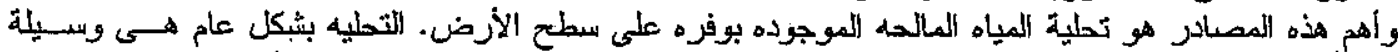

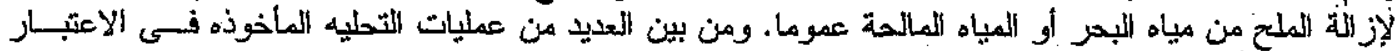

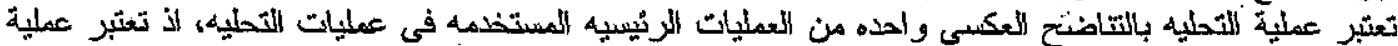

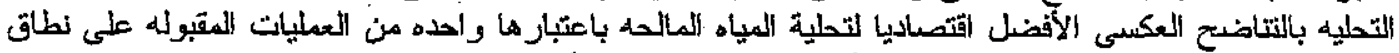

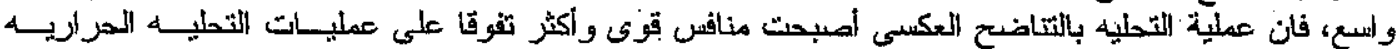
الثقليديه عند مقارنتها من ناحية استهلالك الطاقها

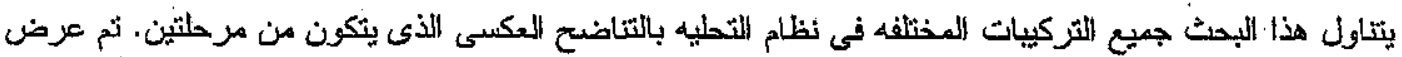

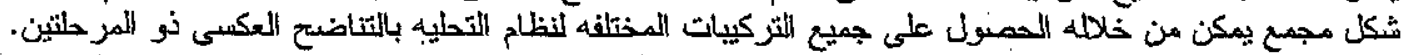

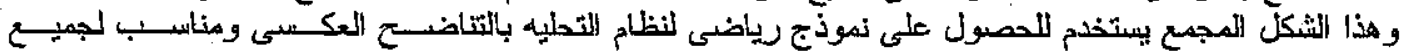

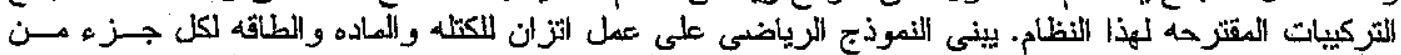

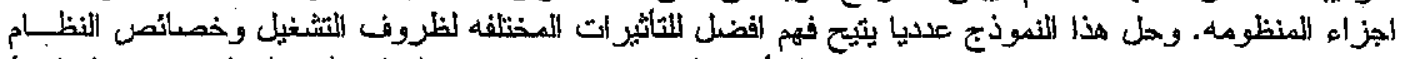

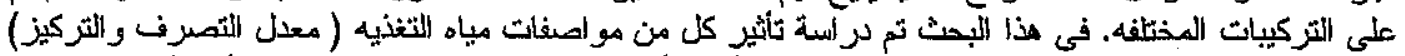

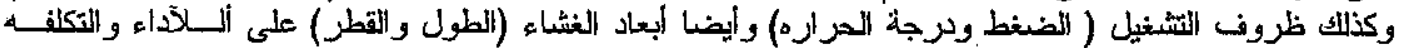

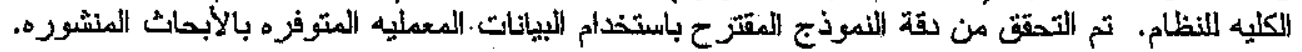

Keywords: Desalination, Reverse osmosis (RO), Mathematical Model, Operating Conditions; Membrane Module

\section{INTRODUCTION}

Desalination is the process of removing salt and other minerals or chemicals from seawater and it is one of the alternative sources for fresh water available today. Desalination provides water for domestic purposes, industrial processing, agricultural irrigation, etc. The most conventional desalination technologies are membrane processes (Reverse Osmosis RO) and Thermal Desalination (Multi Stage Flash (MSF) and Multi Effect Evaporation (MEE) systems). The membrane treatment process used to separate dissolved solutes from water and describes any pressure-driven membrane that uses preferential diffusion for separation: Reverse osmosis and electrodialysis are the two most important membrane processes. The seawater reverse osmosis (RO) desalination is an attractive and viable method for the production of fresh water in many areas, [1].

Several studies have been carried out to investigate the characteristics and performance of RO desalination systems. Metaiche and Kettab, [2] have employed a mathematical model of seawater and 
brackish water desalination systems utilizing a single stage reverse osmosis process. This model yields to improve their design optimization techniques. Guria et al., [3] have carried out multi-objective optimization using genetic algorithm for the desalination of brackish and seawater using spiral wound or tubular modules. It is observed that the membrane area is the most important decision variable in designing a spiral wound module for desalination of brackish water as well as seawater. The pressure difference is also the most important decision variable in designing a tubular module for the desalination of brackish water. Voros et al., [4] have developed a design method for reverse osmosis seawater desalination systems. The effect of the quality and the quantity of the plant productivity on the annualized total cost of the plant was investigated. Wilt and Bartels, [5] have described the configuration and operating parameters of current large seawater desalination systems. A new process approach and some examples of process optimization resulting in lower power consumption and more efficient system operation are presented. Lu et al., [6] have presented the design of various multistage RO systems under different feed concentration and product specification. The solution includes optimal arrangement of the RO modules, pumps, energy recovery devices, the optimal operating conditions, and the optimal selection of types and number of membrane elements. Villafafil and Mujtaba, [7] have studied the RO-based desalination process. They have developed computer programs to analyze the effect of the operating and design parameters on the recovery ratio and the efficiency of the system. An optimization framework for the process is developed so as to maximize the recovery ratio or a profit function using different energy recovery devices, subject to general constraints. The optimal operating parameters are determined by solving the optimization problem. Kahdim et al., [8] have aimed to develop a theoretical model to predict the performance of reverse osmosis (RO) systems and to compare the theoretical results with experimental values obtained from a pilot plant at Basrah University. Agreements between theoretical and experimental results have been noted. Gelsler et al., [9] have optimized of the energy demand of reverse osmosis with a pressure-exchange system (PES). The PES is suited for plants with a permeate production of more than $2000 \mathrm{~m}^{3} /$ day. It enables a simple design and direct transmission of high pressure from the brine to the feed with efficiency of approximately $98 \%$. This proven system has been used in the field of mining for more than 20 years, and with volume flow rate up to $1400 \mathrm{~m}^{3} / \mathrm{h}$ and pressures up to 16 MPa. Hatfield and Graves, [10] have developed a mathematical model of a reverse osmosis system for desalination of brackish water. The solution pointed out a number of important things; most significant of which is that by using modern computing machines and optimization techniques, substantial gains can be made in reducing the size of reverse osmosis systems and thus reducing the cost of the water produced. Nisan et al., [11] have summarized the investigations on the studies of the Reverse Osmosis (RO) process with preheating of the feed-water, which is expected to lead to lower specific power consumption and higher water production.

The present paper aims to develop a mathematical model of two-module reverse osmosis system for brackish and sea water. This model is suitable for all two module arrangements. Effect of feed specifications (feed flow rate and feed concentration), operating conditions (feed pressure and feed temperature) and membrane dimensions (membrane length and membrane channel diameter) on the system performance and it's cost is investigated.

\section{TWO-MODULE RO SYSTEM ARRANGEMENTS}

Several arrangements of two-module feed forward RO systems with and without bypass streams and energy recovery were investigated as shown in Fig.1. The membrane module is modeled as a tube side feed flow tubular module. A superstructure that incorporates all possible arrangements for two module feed forward RO systems is developed in Fig.1. This superstructure is used to develop the general mathematical model for the RO system which can be used to simulate any of the module arrangements shown in Fig. 2.

In the RO system model, the independent variables can be categorized into optimized variables, whose values are changed during optimization, and parameters, whose values are kept fixed. The optimized variables consist of the structural variables, which determine the RO module arrangement and stream distribution in the system, and the design values, which determine the $\mathrm{RO}$ module dimensions and supply pressures. The parameters, whose values are. fixed during optimization, are the feed flow rate, concentration and pressure, the system operating temperature and the membrane specifications characteristics such as membrane water permeability $\left(A_{m}\right)$ and membrane salt rejection (R).

\section{SYSTEM REPRESENTATION}

In - order to formulate a desalination process configuration problèm as a mathematical optimization problem, a representation that contains all possible designs which are considered as candidates for the optimal solution has to be developed. The RO system investigated are all feed 
forward systems with no recycle streams. Thus, there is no set of units that have to be solved simultaneously. The mass, materials and energy balances of the units can be solved sequentially from the feed stream to the product streams. A general superstructure that could simply be reduced to yield all possible amangements has been designed this superstructure uses three split ratios which control the quantity and concentration of the water needed to the second module according to the following equations. For the range of concentration and working temperature used in this study the variation of density can be neglected, see Fig. 3.

$$
\begin{aligned}
Q_{f 2}= & X_{f} \times Q_{f}+X_{r} \times Q_{r 1}+X_{p} \times Q_{p 1} \\
C_{f 2}= & \frac{X_{f} \times Q_{f} \times C_{f}+X_{r} \times Q_{r 1} \times C_{r 1}}{Q_{f 2}} \\
& +\frac{X_{p} \times Q_{p 1} \times C_{p 1}}{Q_{f 2}}
\end{aligned}
$$

The second module could be fed directly from the feed stream. It could also be fed by the retentate or. permeate emerging from the first module.

For example, in Fig. 1-a, all the feed stream flows into the first module. Then, all the retentate of the first modules goes directly to the' second module. Finally, the permeate of the two modules are mixed to give the output. This can be obtained from the superstructure by putting both $\mathrm{Xf}$ and $\mathrm{Xp}$ equal to zero and setting $\mathrm{Xr}=1$. Accordingly, all candidate designs could be deduced from the superstructure employing the values for split ratios presented in Table 1.

All arrangements can be divided into two main groups. The first group targets the retentate. The retentate of the first module is either splitted or taken as it is and admitted to the second module for reprocessing. Thus, the group is called retentate reprocessing arrangement. It includes designs for the system given in Figs. 1-a to 1-e where the arrangement, given in Fig. 1-b, has a special case where the feed is divided over the two modules. The value of permeate split ratio $(\mathrm{Xp})$ is equal to zero in this group. The second group designs for Figs. 1-f to $1-i$ and is called permeate re-processing arrangements. In this group the value of retenate split ratio $(\mathrm{Xr})$ equals zero.

\section{MATHEMATICAL MODEL OF UNIT OPERATIONS}

A mathematical model describing the whole RO system has been derived. The model based on; mass, material and energy balances for the superstructure shown in Fig. 2. The balance equations have been calculated separately for each unit in operation. Membrane modules, pumps, mixers and splitters with complete information about the unit operations and stream properties are considered and then, the performance of the RO system can be investigated. Furthermore, the economic viability of the system can also be studied.

\subsection{Membrane Module}

The membrane module shown in Fig. 4. The mass balance for the membrane is given by;

$Q_{p}=j_{w} \times A$

The volume flow rate of retantate could be calculated as follows:

$Q_{r}=Q_{f}-Q_{P}$

The material balance for the membrane modules is expressed as:

$R=1-\frac{C_{p}}{C_{f}}$

The retantate concentration is computed as:

$C_{r}=\frac{C_{f} \times Q_{f}-C_{p} \times Q_{p}}{Q_{r}}$

The energy balance for the membrane module is written as:

$P_{r}=P_{f}-\Delta P_{\text {in }}-\Delta P_{\text {out }}-\Delta P_{f}$

The flux through the membrane is calculated, [12]

$j_{w}=A_{m} \times P_{e f f}$

The concentration on the feed side membrane wall can be calculated as follows, [12]

$C_{w}=C_{p}+\left(\frac{C_{f}+C_{r}}{2}-C_{p}\right) e^{\frac{j}{k}}$

Residual transmembrane pressure can be obtained from the following equation, [12]

$P_{\text {eff }}=\left(P_{f}-P_{p}-\Delta P_{i n}-\frac{\Delta P_{f}}{2}\right)-\left(\pi_{w}-\pi_{p}\right)$

Equations (8) to (10) can be ușed for tube side feed flow tubular and hollow fiber modules as well as spiral wound module.

The osmotic pressure $(\pi)$ in $\mathrm{Pa}$ as a function of the salt concentration and temperature may be given as in [13] as follows;

$\pi(C, T)=(0.6955+0.0025 T) \times 10^{8} \frac{C}{\rho}$

The mass transfer coefficient $(\mathrm{k})$ is calculated using the following equations, [14]:

For laminar flow $(\operatorname{Re} \leq 2100)$

$k=1.62 \times\left(\frac{\operatorname{Re} \times S c \times d_{c h}}{l_{c h}}\right)^{0.33} \times \frac{D_{s}}{d_{c h}}$. 
For turbulent flow $(\operatorname{Re}>2100)$

$$
k=0.023 \times \operatorname{Re}^{0.875} \times S c^{0.25} \times \frac{D_{s}}{d_{c h}}
$$

The pressure drop in the membrane module consists of pressure losses in the inlet and outlet module manifolds $\left(\Delta P_{\text {in }}\right.$ and $\left.\Delta P_{\text {out }}\right)$ and inside the membrane channel $\left(\Delta \mathrm{P}_{\mathrm{f}}\right)$. Pressure drop in the membrane channel is calculated using the fanning equation, [15].

$$
\Delta P_{f}=2 \times f \times \rho \times V_{c h}^{2} \times \frac{l_{c h}}{d_{c h}}
$$

Then $f$ (fanning friction factor) is a function of the Reynolds number (Re), approximated with the relations for smooth bore pipes, [15]:

For laminar flow $(\operatorname{Re} \leq 2100)$ :

$f=\frac{16}{\operatorname{Re}}$

For turbulent flow $(\operatorname{Re}>2100)$

$f=\frac{0.0791}{\operatorname{Re}^{0.25}}$

The density of sea water is computed as follows, [13]

$$
\rho=498.4 m+\sqrt{248400 m^{2}+752.4 m C}
$$

Where

$$
m=1.0069-2.757 \times 10^{-4} T
$$

The viscosity of sea water in Pa.s. is expressed as, [13]

$$
\mu=1.234 \times 10^{-6} \exp \left(0.00212 C+\frac{1965}{(T+273.15)}\right)
$$

The diffusivity of seawater in $\mathrm{m}^{2} / \mathrm{s}$ is given as in [13] as follows;

$$
D=6.725 \times 10^{-6} \exp \left(0.1546 \times 10^{-3} C-\frac{2513}{(T+273.15)}\right)
$$

Pressure drop in the inlet module manifold is treated as a series of sudden expansions from the feed pipeline into the module shell and sudden contractions from the module shell into each membrane channel. Similarly, pressure drop in the outlet module manifold is a series of sudden expansions from the membrane channel into the module shell and sudden contraction from the module shell into retenate pipeline. The general pressure drop equations fro sudden expansions $\left(\Delta \mathrm{P}_{\mathrm{ex}}\right)$ and contractions $\left(\Delta \mathrm{P}_{\mathrm{co}}\right),[15]$ are:

$$
\begin{aligned}
\Delta P_{e x} & =\left(1-\frac{A_{1}}{A_{2}}\right)^{2} \frac{V^{2} \rho}{2 \alpha} \\
\Delta P_{c o} & =0.55\left(1-\frac{A_{1}}{A_{2}}\right)^{2} \frac{V^{2} \rho}{2 \alpha}
\end{aligned}
$$

\section{Where:}

$\alpha=1$ for $\operatorname{Re}>2100$ and $\alpha=0.5$ for $\operatorname{Re} \leq 2100$.

Combination and modification of these equations to suit inlet and outlet manifolds for tubular modules results in:

$$
\begin{aligned}
& \Delta P_{t h}=\left(\left(1-\frac{A_{p}}{A_{s h}}\right)^{2} V_{p}^{2}+0.55\left(1-\frac{n \times A_{c h}}{A_{t h}}\right)^{2} V_{c h}^{2}\right) \frac{\rho}{2 \alpha} \\
& \Delta P_{o u t}=\left(\left(1-\frac{n \times A_{c h}}{A_{s h}}\right)^{2} V_{i h}^{2}+0.55\left(1-\frac{A_{p}}{A_{s}}\right)^{2} V_{p}^{2}\right) \frac{\rho}{2 \alpha}
\end{aligned}
$$

\subsection{Pump}

There is no change in the flow rate or concentration of the stream leaving the pumps, thus:

$Q_{o}=Q_{t}$

$C_{o} \doteq C_{i}$

The pump efficiency is assumed to be $65 \%,[14]$ :

$W_{p}=Q_{i} \frac{P_{o}-P_{i}}{0.65}$

\subsection{Mixer}

The mass balance for a mixer is expressed using Fig.5 as follows:

$Q_{o}=\sum_{i=1}^{n} Q_{i}$

The materials balance for a mixer is described as:

$C_{o}=\frac{\sum_{i=1}^{n} C_{i} \times Q_{i}}{Q_{o}}$

The outlet pressure from the mixer is the smallest inlet pressure to the mixer minus the pressure drop in the mixer.

$P_{0}=\min \left\{P_{i}-\Delta P_{i}\right\}, i=1,2,3$

Where $i$, is the number of each stream

The pressure drop in the mixer is calculated as the pressure drop in a tee, [15]:

$\Delta P_{i}=\alpha \times \rho \times \frac{V_{i}^{2}}{2}$

Where:

$\alpha=1.4$ for $\operatorname{Re} \leq 2100$ and $\alpha=1$ for $\operatorname{Re}>2100$

\subsection{Splitter}

For a specified split tatio (X), the outlet stream from splitter can be determined as shown in Fig. 6 by;

$Q_{o}=X \times Q$

The outlet pressure is the inlet pressure minus the 
pressure drop in the splitter.

$P_{o}=P_{l}-\Delta P_{t}$

The pressure drop is calculated using Eqn (31).

\section{RO SYSTEM'S COST}

For the RO system, the overall cost was defined as the total of all capital and operating cost. The cost can be calculated as follow:

$$
\begin{aligned}
\text { Cost }= & C_{m e m} A+C_{\text {main }} A+C_{\text {pump }}\left(\frac{Q_{w} \Delta P}{W_{\text {base }} \eta}\right)^{n} \\
& +\frac{C_{\text {ele }} Q_{w} \Delta P}{\eta}
\end{aligned}
$$

Substituting the appropriate cost coefficients and $\eta=0.65,[3]$, one obtains

$$
\begin{aligned}
& \text { Cost }=1.946 \times 10^{-3} A+3.57 \times 10^{-3} A+ \\
& 0.0943\left(0.02234 Q_{f} \Delta P\right)^{0.67}+0.08334 Q_{f} \Delta P
\end{aligned}
$$

\section{RESULTS AND DISCUSSIONS}

\subsection{Effect of Feed Pressure on Unit Performance}

The feed pressure to module 1 has been changed from 40 to 150 bars. The effects of feed pressure on both permeate and a retentate flow rate for arrangement (e) shown in Fig. 1 is shown in Fig. 7 and 8 respectively. In this arrangement, the feed to module 2 is partially from the feed to the unit and partially from the retentate of module 1 . The figures. show that, as the feed pressure increases, the permeate of module 1 increases due to the increase in the effective net pressure across the membrane (transmembrane pressure) while the retentate flow rate decreases. The permeate and the retentate of module 2 decrease slightly. This can be attributed to the decrease in the retentate flow rate of module 1. Consequently, the rate of feed to module 2 decreases. As a result, the total permeate of the arrangement increases with feed pressure and the total retentate decreases.

A comparison between all retentate reprocessing arrangements shown in Fig. 1 is given in Fig. 9 for total permeate and retentate flow rate. All arrangements yield the same pattern of variation with feed pressure. The differences in flow rates in case of arrangements ( $a, c, d$, and $e$ ) are small. However, in arrangement (b), the permeate flow rate is much smaller and retentate flow rate is much higher at lower feed pressures. In the latter arrangement (parallel arrangement), the feed pressure to the two modules is equal. Thus, at low pressures, the permeate is expected to be small. However, in other arrangements, the feed pressure to the module 2 is kept constant at a value higher than the feed pressure to module $l$ as it handles a feed with less flow rate but with higher concentration. Based on Fig. 9, arrangement (a) seems to be the best arrangement as far as productivity is concerned.

The variation of permeate and retentate flow rates with feed pressure to module 2 is presented in Fig.10 and 11 for arrangement (e). Since the feed pressure, flow rate and concentration for module 1 are constant, the permeate and retentate flow rates are also constant. As the feed pressure to module 2 increases, the permeate of this module increases and the retentate decreases. Consequently, the overall permeate flow rate of the unit is increasing and the retentate flow rate decreases.

Figure 12 shows the variation of permeate concentration with feed pressure of module 1 for arrangement (e). It is seen that, as the feed pressure increases, the permeate concentration of module 1 is constant while the permeate concentration of module 2 increases. This is anticipated since the feed concentration for module 1 is constant while it increases for module 2 . The retentate concentration of module 1 increases due to the decrease of retentate flow rate with feed pressure. As a result, the total permeate concentration increases with feed pressure. A' comparison between all retentate re-processing arrangements is given in Fig. 13 for total permeate concentration. In arrangements ( $a, c, d$ and.e), the permeate concentration increases as the feed pressure increases. Arrangement (e) gives lower concentration. In arrangement (b) (parallel axrangement), the total permeate concentration is constant because the feed concentration for two modules are equal and constant.

The effect of feed pressure on the retentate concentration is presented in Fig. 14 for arrangement (e). It can be noticed that the retentate concentration for the two modules increases with increasing the feed pressure because the retentate flow rate for each module decreases. Also, the retentate concentration is bigher for module 2 than module 1 , because the feed concentration for the module 2 is greater than that for module 1. As a result, the total retentate concentration increases with increasing the feed pressure. A comparison between all retentate reprocessing arrangements is given in Fig. 15 for total retentate concentration. All arrangements' show similar trends of variation with feed pressure. For arrangements (a, c, d, and e), the differences in total retentate concentration are small. However, in arrangement (b), the total retentate concentration is much smaller at lower feed pressure.

Figure 16 displays the effect of feed pressure to module 1 on the overall cost of the system for arrangement (e). With increasing the feed pressure to module 1 , the cost of module 1 increases and the cost of module 2 decreases. When the feed pressure to module 1 increases, the power required to the first 
pump increases. However, the retentate pressure of module 1(feed pressure to second pump) increase. So the power required for the second pump decreases. As a result, the total cost increases. A comparison of overall cost between all retentate re-processing arrangements is presented in Fig. 17. In arrangements (a and d), the pressure difference across the pump and the feed flow rate are equal so, the required power is equal; this consequently the total cost is the same. Similar trend is noticed for arrangements (c and e). The cost of arrangements ( $a$ and $d$ ) is higher than that for arrangements ( $c$ and $e$ ), which in turn is higher than that for arrangement (b). The reason for the lower cost of arrangement (b) is the use of only one pump.

Figure 18 presents the effect of feed pressure to module 1 on the recovery ratio for all retentate reprocessing arrangements. With increasing the feed pressure, the recovery ratio increases because of the increased permeate flow rate for an almost constant feed flow rate. All arrangements yield the same pattern of variation with feed pressure and the arrangement (a) gives a higher recovery ratio while arrangement (b) gives a lower recovery ratio and it's much smaller at lower feed pressure.

\subsection{Effect of Feed Concentration on . Unit Parameters}

The feed concentration to module 1 has been changed from 2 to $45 \mathrm{~kg} / \mathrm{m} 3$. The effects of feed concentration on both permeate and retentate flow rate for arrangement (e) is shown in Figs. 19 and 20 respectively. As the feed concentration increases, the osmotic pressure at the membrane wall increases, leading to a reduction in the effective net pressure across the membrane. Thus, the permeate of module 1 decreases. This results in an increase in the concentration of feed to module 2 . Consequently, the permeate of module 2 decreases too as shown in Fig.19. Based on the conservation of mass principles, a decrease in the permeate flow rate should be accompanied by an increase in the retentate flow rate as shown in Fig. 20. It can be observed also that the rate of increase in retentate flow rate is higher in module 2 than that in module 1.

A comparison between all retentate re-processing arrangements is given in Fig. 21 for total permeate and retentate flow rate. All arrangements yield the same pattern of variation with feed concentration. The differences in flow rates for all cases of arrangements are small. Arrangement (a) gives the higher value for permeate flow rate and arrangement (b) gives the lower value. The arrangements for retentate flow rate is exactly the opposite of those of permeate.

The variation of permeate and retentate concentration with feed concentration to module 1 for arrangement (e) is shown in Fig. 22. The figure shows the increase in the feed concentration leads to an increase in the permeate and the retentate concentration for module 1. For module 2 the feed concentration increases, the permeate and the retentate concentration increases. The permeate and the retentate concentration for module 1 is higher than that for module 2 because the feed concentration to module 2 is higher than that for module 1. As a result, the total permeate and retentate are increasing. A comparison between all retentate re-processing arrangements is given in Fig.23 for total permeate concentration and in Fig.24 for total retentate concentration. All arrangements yield the same pattern with feed concentration and the difference between all arrangements is much small.

Figure 25 shows the variation of recovery ratio with feed concentration to module 1 for all retentate reprocessing arrangements. The figure shows that the recovery ratio decreases drastically with increasing the feed concentration. As feed concentration increases, due to the permeate flow rate decreases for a fixed feed flow rate, the recovery ratio decreases. All arrangements have the same pattern in variation. Arrangement (e) gives higher value of recovery ratio, while arrangement (b) gives lower value of recovery ratio.

\subsection{Effect of Feed Flow Rate on Unit Performance}

The feed flow rate to module 1 has been changed from 30 to $100 \mathrm{~m} 3 / \mathrm{hr}$. The effects of feed flow rate on both permeate and retentate flow rate for arrangement (e) is shown in Figs. 26 and 27 respectively. These figures show that, as the feed flow rate increases, the permeate and the retentate for two modules are increasing. The percentage increase in permeate is smaller than that in retentate. Also; the permeate for module 1 is higher than that of module 2 , this is due to the higher feed concentration of module 2. The opposite is noticed for retentate flow rate.

A comparison between all retentate re-processing arrangements is given in Fig. 28 for total permeate and retentate flow rate. All arrangements yield to the same pattern of variation with feed flow rate. Arrangement (a) gives higher value of permeate flow rate and the arrangement (b) gives lower value of permeate flow rate. The arrangements for retentate flow rate is exactly the opposite for those of permeate. The differences between arrangements for retentate flow rate are hardly noticed.

The variation of permeate and retentate concentration with feed flow rate to module 1 for arrangement (e) is shown in Figs. 29 and 30 respectively. With increasing in the feed flow rate, the permeate concentration is constant for module 1 while it decreases for module 2 as shown in Fig. 29. This is 
due to the feed concentration for module 1 is constant while it decreases for module 2 . Also, the permeate concentration for module 2 is higher than that of module 1 . This is because the feed concentration to module 2 is higher than that of module 1 . Figure 30 indicates that, increasing the feed flow rate decreases the retentate concentration for both modules. The reason for this is; as the feed flow rate increases, the retentate flow rate increases. And the result of this, the total permeate and retentate concentration is decreasing.

A comparison between all retentate re-processing arrangements is given in Fig. 31 for total permeate concentration and for total retentate concentration in Fig. 31. In Fig. 31, in arrangements (a, c, d and e), the permeate concentration decreases as the feed flow rate increases. Arrangement (e) gives lower concentration. In arrangement (b) (parallel arrangement), the total permeate concentration is constant because the feed concentration for two modules are equal and constant. All arrangements. show similar trends with very small differences as shown in Fig. 32.

Figure 33 presents the variation of total cost with feed flow rate to module 1 for arrangement (e). From the figure, as the feed flow rate increases, a large increase is seen in the cost of module 1 while the change in the cost of module 2 is very small. This is due to the increases in the power required for the first pump as the feed flow increases. As a result the total cost of overall system increases. A comparison between all retentate re-processing arrangements for total cost is shown in Fig. 34. The same pattern is noticed for all arrangements and no significant change in total cost between the various arrangements. The same results are also applicable for retentate processing arrangements.

The effect of feed flow rate on the recovery ratio for all retentate re-processing arrangements is illustrated in Fig. 35. With increasing the feed flow rate the recovery ratio decreases. As the feed flow rate increases, the permeate flow rate increases. But the increasing value in permeate flow rate is smaller than that in feed flow rate. Thus, the recovery ratio is decreased. All arrangements have the same trend but smaller differences between them.

\subsection{Effect of Feed Temperature on Unit Performance}

The feed temperature to the system has been chianged from 20 to $50^{\circ} \mathrm{C}$. The effect of feed temperature on both permeate and retentate flow rate for all retentate re-processing arrangements is shown in Fig. 36. This figure shows that by increasing the feed temperature, the total permeate flow rate increases. As feed temperature increases, the viscosity of water decreases and the Reynolds number increases. Thus the mass transfer coefficient increases and salt concentration on membrane wall decreases. As a result, the permeate flow rate increases as well. The total retentate flow rate slightly decreases. This is because the feed flow is constant and the permeate flow rate increases. The figure indicates also that all arrangements bave the same pattern of variation. The arrangement (a) gives a higher permeate flow rate while the arrangement (b) gives a lower permeate flow rate. The arrangements for retentate flow rate is exactly the opposite for those of permeate flow rate

The effect of feed temperature on permeate and retentate concentration for all retentate re-processing arrangements is given in Fig. 37 and 38 respectively. In Fig. 37 it is noticed that, with increasing the feed temperature, the total permeate concentration is slightly increases in all arrangements except arrangement (b). The permeate concentration for arrangement (b) (parallel arrangement) is almost constant. In Fig. 38 as the feed temperature increases, the total retentate concentration increases. All arrangements give the same pattern of variation. Arrangement (a) gives a higher value for total permeate and retentate concentration while the arrangement $(b)$ gives a lower value for permeate and retentate concentration.

The variation of recovery ratio with feed temperature is presented in the Fig. 39 for all retentate reprocessing arrangements. It can be observed that as the feed temperature increases, the recovery ratio increases. This is due to an increase in permeate flow rate. In general, all arrangements have the same pattern of variation and a large difference between them. The arrangement (a) gives a higher value of recovery ratio while the arrangement (b) gives a lower value of recovery ratio.

\subsection{Effect of Module Dimensions on Unit Performance}

The main module dimensions are tube length, diameter and number of tubes. The total membrane area can be calculated as:

$A=n \times \pi \times d_{c h} \times l_{c h}$

To study the effects of module dimension on the unit performance, changed the module length and diameter. The length of module 1 has been changed from 0.05 to $1 \mathrm{~m}$ according to the membrane surface area which changed from 6.4 to $128.8 \mathrm{~m}^{2}$. The channel diameter for module 1 has been changed from 0.05 to $1.2 \mathrm{~mm}$ according to the membrane surface area which changed from 4.7 to $56: 5 \mathrm{~m}^{2}$. While the number of tubes is kept constant in two cases.

The effect of length of module 1 on both permeate and retentate flow rate for arrangement (e) is shown in Fig. 40 and 41 respectively. By increasing the 
length of module 1 , the permeate flow rate for module 1 increases while the retentate flow rate for module 1 decreases. This is due to, as the length of module 1 increases the total surface area of module 1 increases thus the permeate flow rate for module 1 increases and the retentate flow rate for module.1 decreases. For module 2, decreasing the retentate flow rate for module 1 decreasing the feed flow rate to module 2 thus a small decreasing in both permeate and retentate for module 2. Finally, the total permeate flow rate increases while the total retentate decreases. The same variation is noticed for change the channel diameter of module 1 as shown in Fig. 42 and 43.

A comparison between all retentate re-processing arrangements for the length of module 1 is illustrated in Fig , 44 for total permeate and retentate flow rate. From the figure all the arrangements have the same pattern of variation. The arrangement (a) gives a higher permeate flow rate and the arrangement (b) gives a lower permeate flow rate. The arrangements for retentate flow rate are exactly the opposite to those of permeate.

The effect of length of module 1 on permeate and retentate concentration is presented in Figs. 45 and 46 respectively. From the figures it is seen that,by increasing the length of module 1 the retentate concentration for module 1 is increasing while the permeate concentration for module 1 is kept constant. As the length of module 1 increases the surface area increases, the permeate flow rate increases while the retentate flow rate decreases and the feed concentration for module 1 is constant. Thus, the retentate concentration for module 1 increases and the permeate concentration is constant. For module 2, increases the retentate flow rate for module 1 yield to increase the feed concentration for module 2, so the permeate and retentate for module 2 increases. Finally, the total permeate and retentate concentration increases.

A comparison between all retentate re-processing arrangements for length of module 1 is illustrated in figure (47) for total permeate concentration and figure (48) for total retentate concentration. In figure (47) as the length of module 1 increases the total permeate concentration for arrangements (a, c, d and e) increases. No changes in the total permeate concentration for arrangement (b) with increasing the length of module 1 . The permeate concentration for arrangement (b) is the lowest compared to other arrangements. Increasing the length of module 1 increasing the total retentate concentration for all arrangements as shown in Fig. 48. The differences between all arrangements are small and arrangement (a) gives a higher retentate concentration while arrangement (e) gives a lower permeate concentration.
The effect of length of module 1 on the recovery ratio of the system is shown in Fig. 49 for all retentate re-processing arrangements. The figure indicates that, the recovery ratio increases as the length of module 1 increases. This is due to increasing the length if module 1 increasing the total permeate flow rate while the feed flow rate is kept constant. The figure shows that all arrangements have the same patterns in variation and arrangement (a) gives a higher recovery ratio while the arrangement (b) gives a lower recovery ratio. The effect of the length of module 1 on the overall system cost is presented in Fig. 50. The figure indicates increasing the length of module 1 increasing the overall cost. This because, by increasing the length of module 1 the area of module 1 increases. This yield to the cost of module 1 increases. Increasing the length of module $l$ the frictional pressure drop increases and the pressure differences for the second pump increases. Thus, the power required to the second pump increases. Accordingly, a small increasing in the cost of module 2. The figure shows, all arrangements have the same pattern of variation and the difference between all arrangements is small. The cost of arrangement (a) is the highest.

\section{COMPARISON WITH PERVIOUS PUBLICATIONS}

In order to verify the model presented here, the results obtained were compared with the previous results. The operating conditions and the system dimensions of the unit reported in $[16,17]$ have been given as an input to the simulation program. The output results have been compared with the corresponding data published in $[16,17]$. The comparison is depicted in Figs. 51 and 52 for permeate flow rate, in Fig. 53 for the power consumption and in Fig. 54 for recovery ratio. It can be noted that the deviation between the theoretical and experimental reported in [16] and the current study is closer to the experimental reported in [16]. Also, the current theoretical results are closer to measurements reported in [17]. The discrepancy between our results and those given in [16] and [17] are due to neglecting the pressure drop and concentration polarization in their work.

\section{CONCLUSIONS}

A parametric study of retentate re-processing $R O$ desalination units has been investigated and the following conclusions could be drawn:

1- Increasing the feed pressure, improves the performance of the unit and increases the cost.

2- As the feed concentration increases, the total permeate from the unite decreases in all arrangements.

3- No noticed change in the unit cost due to change 
in feed concentration.

4- No noticed improvement in unit performance due to the feed flow rate increase.

5- Increasing the feed flow rate yields to increase in the unit cost.

6- The surface area is strongly affects the performance of RO system. While the negative effect due to increasing of unit dimensions is ignored.

7- The membrane area is the most important decision variable in the $\mathrm{RO}$ system

\section{REFERENCES}

[1] Sourirajan S., "Reverse Osmosis". Logos Press Limited, 1970.

[2] Metaiche M. and Kettab A., "Mathematical modeling of desalination parameters: mono-stage reverse osmosis", Desalination 165, pp.153, 2005.

[3] Guria C., Bhattacharya P. K. and Gupta S. K., "Multi-objective optimization of reverse osmosis desalination units using different adaptations of the non-dominated sorting genetic algorithm (NSGA)" Computers and Chemical Engineering 29, pp.1977-1995, 2005.

[4] Voros N., Maroulis Z.B. and Marinos-Kouris D., "optimization of reverse osmosis networks for seawater desalination". Computers chem. Engng Vol. 20, Suppl., pp. S345-S350, 1996

[5] Wilt M. and Bartels C., "Optimization of seawater RO systems design". Desalination 173, pp.1-12, 2005.

[6] Lu Y.Y., Hua Y. D., Zhang X.L., Wu L.Y. and Liu Q.Z., "Optimum design of reverse osmosis system under different feed concentration and product specification". Journal of Membrane Science 287, pp.219-229, 2007.

[7] Villafafil A. and Mujtaba I.M., "Fresh water by reverse osmosis based desalination: simulation and optimisation". Desalination 155, pp.1-13, 2003.

[8] Kahdim A. S., Ismail S. and Jassim A. A., "Modeling of reverse osmosis systems". Desalination 158, pp. 323-329, 2003.

[9] Gelsler P., Krumm W. and Peters T., "Optimization of the energy demand of reverse osmosis with a pressure-exchange system" Desalination 125, pp. 67-172, 1999.

[10] Hatfield G. B. and Graves G.W., "optimization of a reverse osmosis system using nonlinear programming". Desalination 7, pp.147-177, 1970.

[11] Nisan S., Commercon B. and Dardour S., "A new method for the treatment of the reverse osmosis process, with preheating of the feed water". Desalination 182, pp.483-495, 2005.

[12] Wilet D.E., Fell C.J.D. and Eane A.G., "optimization of membrane module design for brackish water desalination", desalination, (1985), Vol. 52, 249-265.

[13] Taniguchi M., Kurihara M. and Kimura S., "Behavior of a Reverse Osmosis Plant Adopting a brine conversion two-stage process and its computer simulation". Journal of Membrane Sciences (2001), Vol. 183, PP. 249-257.

[14] Maskan F., Wlley D. E., Johnston L.P.M. and Celements D. J., "optimal design of reverse osmosis module networks", AICHE Journal, May (2000), Vol.46, No.5.

[15] Warring and Horace R., "Valves, Piping and Pipelines Handbook". 2nd ed., Elsevier Advanced Technology, Oxford, UK, 1996.

[16] Al- Bastaki N.M. and Abbas A., "Predicting the performance of RO Membranes", desalination, (2000), Vol. 132, 181-187.

[17] Chen J. and Li. G, "Marine Reverse Osmosis Desalination Plant-a Case Study", desalination, (2005), Vol. 174, 299-303.

\section{NOMENCLATURE}

A Membrane area, $\mathrm{m}^{2}$

$A_{\text {ch }}$ Cross Sectional Area of the Membrane Channel, $\mathrm{m}^{2}$

$\mathrm{A}_{\mathrm{m}} \quad$ Membrane Water Permeability, $\mathrm{m} / \mathrm{s} . \mathrm{kPa}$

$A_{\text {sh }}$ Cross Sectional Area of the Module's Shell Part, $\mathrm{m}^{2}$

$A_{p}$. Cross Sectional Area of the Pipe, $\mathrm{m}^{2}$

$\mathrm{C}_{\mathrm{f}}$. Feed Concentration, $\mathrm{Kg} / \mathrm{m}^{3}$

$\mathrm{C}_{\mathrm{f} 2}$ concentration of feed water to $2^{\text {nd }}$ module, $\mathrm{Kg} / \mathrm{m}^{3}$

$\mathrm{C}_{\mathrm{r}} \quad$ Total Retentate Concentration, $\mathrm{Kg} / \mathrm{m}^{3}$

$\mathrm{C}_{\mathrm{r} 1} \quad$ Retentate Concentration from $1^{\text {st }}$ Module, $\mathrm{Kg} / \mathrm{m}^{3}$

$\mathrm{C}_{\mathrm{t} 2}$ Retentate Concentration from $2^{\text {nd }}$ Module, $\mathrm{Kg} / \mathrm{m}^{3}$

$\mathrm{C}_{\mathrm{p}} \quad$ Total Permeate Concentration, $\mathrm{Kg} / \mathrm{m}^{3}$

$\mathrm{C}_{\mathrm{p} 1}$. Permeate Concentration from $1^{\text {st }}$ Module, $\mathrm{Kg} / \mathrm{m}^{3}$

$\mathrm{C}_{\mathrm{p} 2}$ Permeate Concentration from $2^{\text {nd }}$ Module, $\mathrm{Kg} / \mathrm{m}^{3}$

$\mathrm{C}_{\mathrm{w}} \quad$ Concentration on the Feed Side Membrane Wall, $\mathrm{Kg} / \mathrm{m}^{3}$

Cost Total Cost, $\$ / \mathrm{hr}$

$\mathrm{d}_{\text {ch }} \quad$ Membrane Channel Diameter, $\mathrm{m}$

$\mathrm{D}_{\mathrm{s}} \quad$ Solute Diffusivity, $\mathrm{m}^{2} / \mathrm{s}$

$\mathrm{j}_{\mathrm{w}}$. Water flux, $\mathrm{m}^{3} / \mathrm{m}^{2} . \mathrm{s}$

$\mathrm{K}$, Mass Transfer Coefficient, $\mathrm{m} / \mathrm{s}$

$\mathrm{L}_{\mathrm{ch}} \quad$ Length of the Membrane Channel, $\mathrm{m}$

$\mathrm{N}$ Number of Membrane Channels

$\mathrm{P}_{\text {eff }} \quad$ Residual Transmembrane Pressure, $\mathrm{kPa}$

$\mathrm{P}_{\mathrm{f}} \quad$ Feed Pressure, $\mathrm{kPa}$

$\mathrm{P}_{\mathrm{r}} \quad$ Retentate Pressure, $\mathrm{kPa}$

$\mathrm{Q}_{\mathrm{f}} \quad$ Feed Flow Rate, $\mathrm{m}^{3} / \mathrm{s}$

$\mathrm{Q}_{\mathrm{f} 2} \quad$ Flow Rate of Feed Water to $2^{\text {nd }}$ Module, $\mathrm{m}^{3} / \mathrm{s}$ 
$\mathrm{Q}_{\mathrm{p}} \quad$ Permeate flow rate , $\mathrm{m}^{3} / \mathrm{s}$

$\mathrm{Q}_{\mathrm{p} 1}$. permeate flow rate from $1^{\text {st }}$ module, $\mathrm{m}^{3} / \mathrm{s}$

$Q_{r} \quad$ Retentate Flow Rate, $\mathrm{m}^{3} / \mathrm{s}$

$\mathrm{Q}_{\mathrm{r} 1} \quad$ Retentate Flow Rate from $1^{\text {st }}$ Module, $\mathrm{m}^{3} / \mathrm{s}$

$\mathrm{R} \quad$ Membrane's solute rejection

$\operatorname{Re}$ Reynolds number

$\mathrm{Sc} \quad$ Schmidt number ( $\mathrm{Sc}$ value is 673-710)

$\mathrm{T} \quad$ Feed Temperature, ${ }^{\circ} \mathrm{C}$

$V_{p} \quad$ Velocity in Pipe, $\mathrm{m} / \mathrm{s}$

$V_{\text {ch }} \quad$ Velocity in Membrane Channel, $\mathrm{m} / \mathrm{s}$

$\mathrm{W}_{\mathrm{p}}$ Energy Required to Operate the Pump, $\mathrm{kW}$

$\mathrm{X}_{\mathrm{f}} \quad$ Feed Split Ratio

$X_{\mathrm{I}} \quad$ Retentate Split Ratio

$X_{p} \quad$ Permeate Split Ratio

$\Delta \mathrm{P} \quad$ Pressure Difference, $\mathrm{kPa}$

$\Delta \mathrm{P}_{\mathrm{f}} \quad$ Pressure Drop due to Friction, $\mathrm{kPa}$

$\Delta \mathrm{P}_{\text {in }} \quad$ Pressure Drop at Inlet, $\mathrm{kPa}$

$\Delta \mathrm{P}_{\text {out }} \quad$ Pressure Drop at Outlet, $\mathrm{kPa}$

\section{Greek symbols}

$\eta \quad$ Pump Efficiency

$\mu \quad$ Feed Water Viscosity

$\pi_{w} \quad$ Osmotic pressure on the feed side membrane wall, $\mathrm{kPa}$.

$\pi_{p}$ Osmotic pressure on the permeate side,

$\mathrm{P} \quad \mathrm{kPa}$ feed side solution density, $\mathrm{Kg} / \mathrm{m}^{3}$

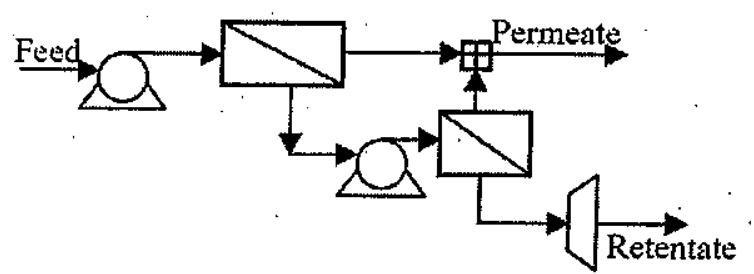

a) Series Arrangement, Retentate Re-processing

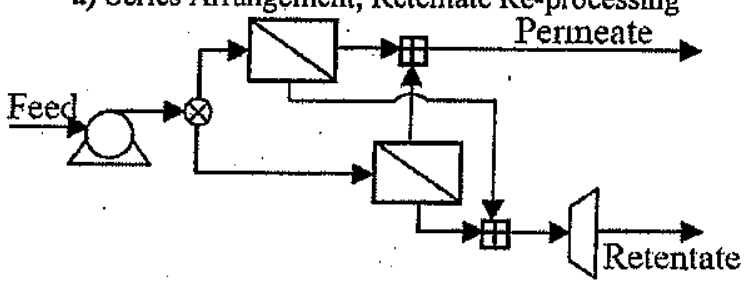

b) Parallel Arrangement

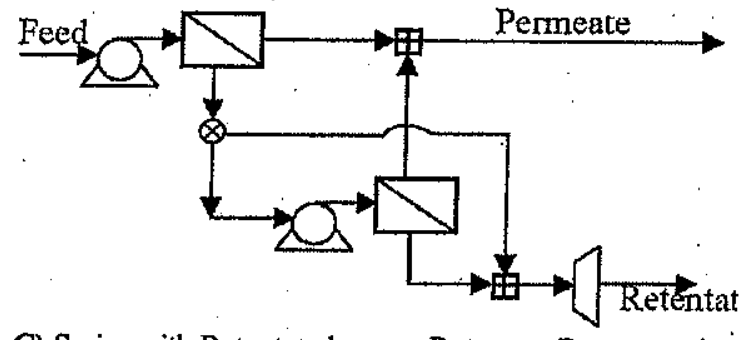

C) Series with Retentate bypass, Retentate Re-processing

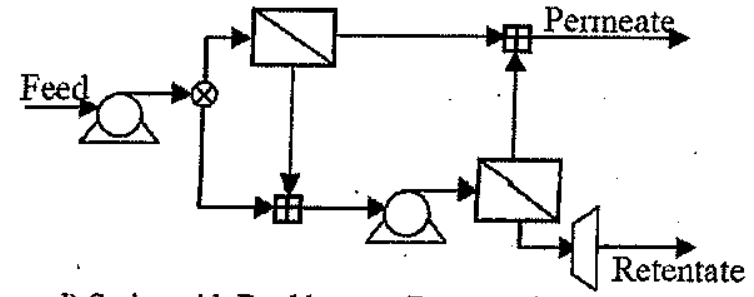

d) Series with Feed bypass, Retentate Re-processing

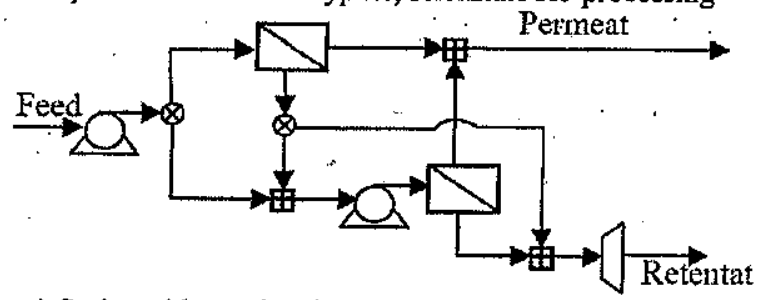

e) Series with Feed and Retentate By pass Retentate Reprocessing

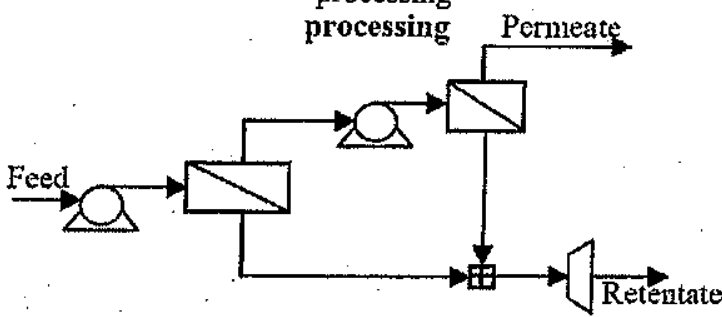

.f) Series Arrangement, Permeate Re-processing

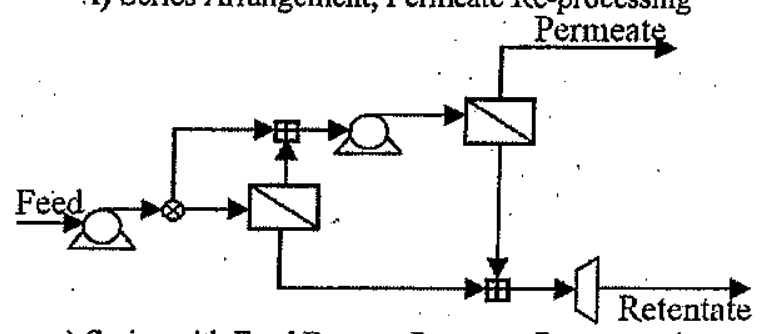

g) Series with Feed Bypass, Permeate Re-processing

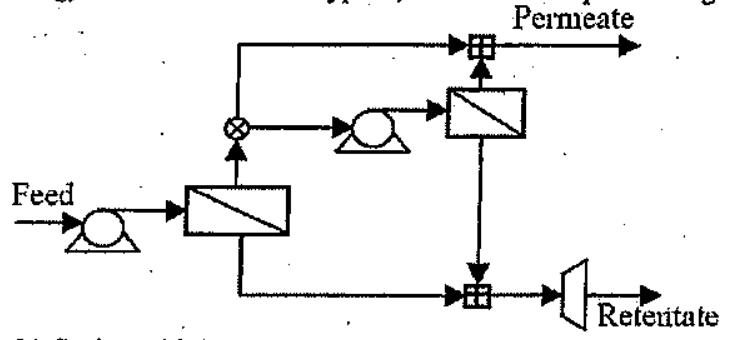

h) Series with Permeate Bypass, Permeate Re-processing

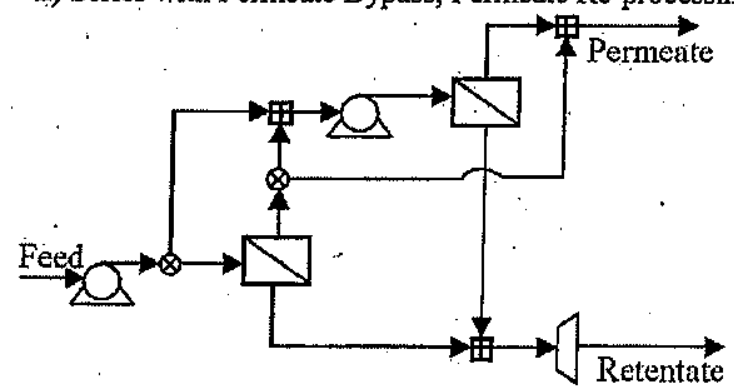

i) Series with Feed and Permeate Bypass, Permeate Reprocessing

Fig. 1 Various Two Module RO Arrangements 


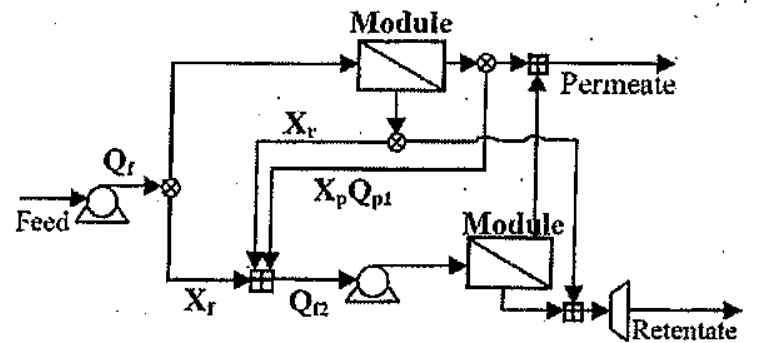

Fig. 2 Superstructure of Two-Module System

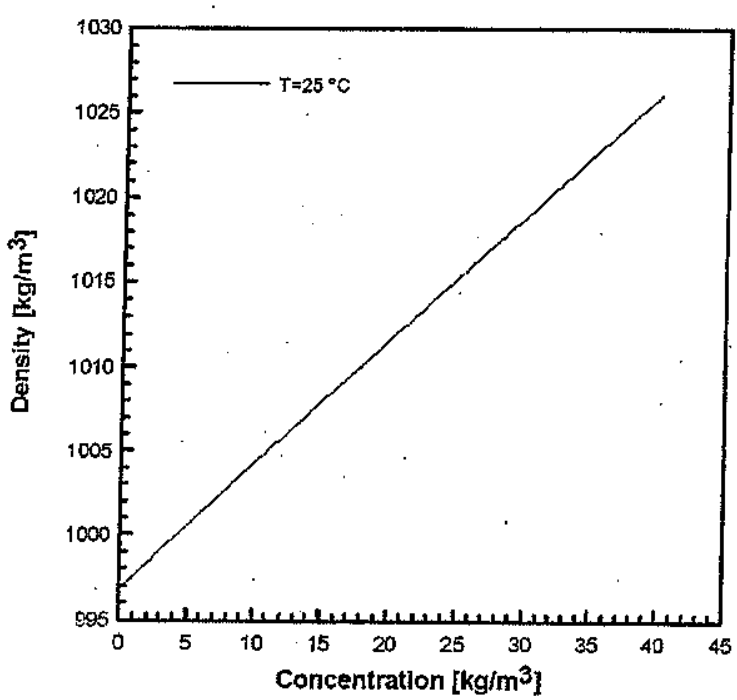

Fig. 3 Variation of Density with Concentration

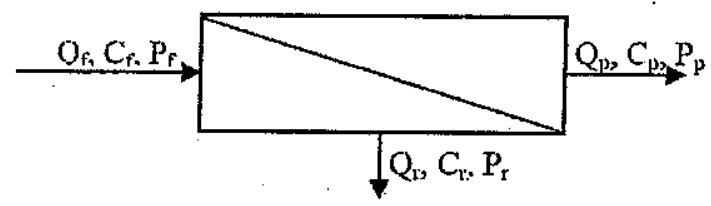

Fig. 4 Membrane Module

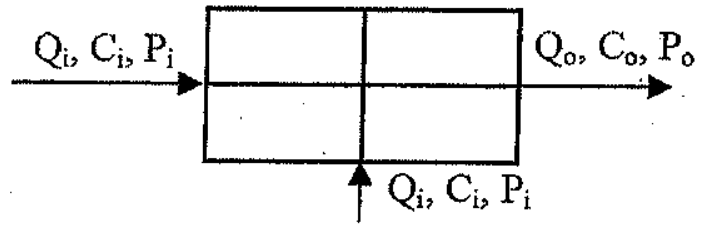

Fig. 5 Mixer Simulation

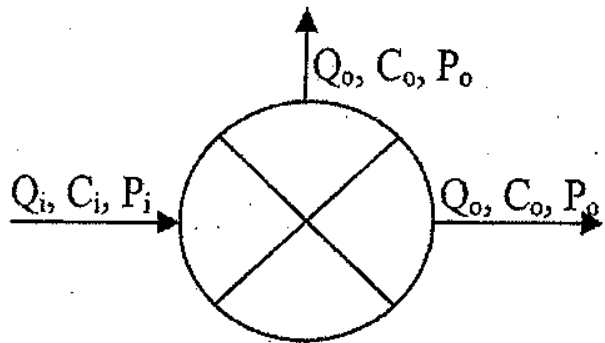

Fig. 6 Splitter Simulation

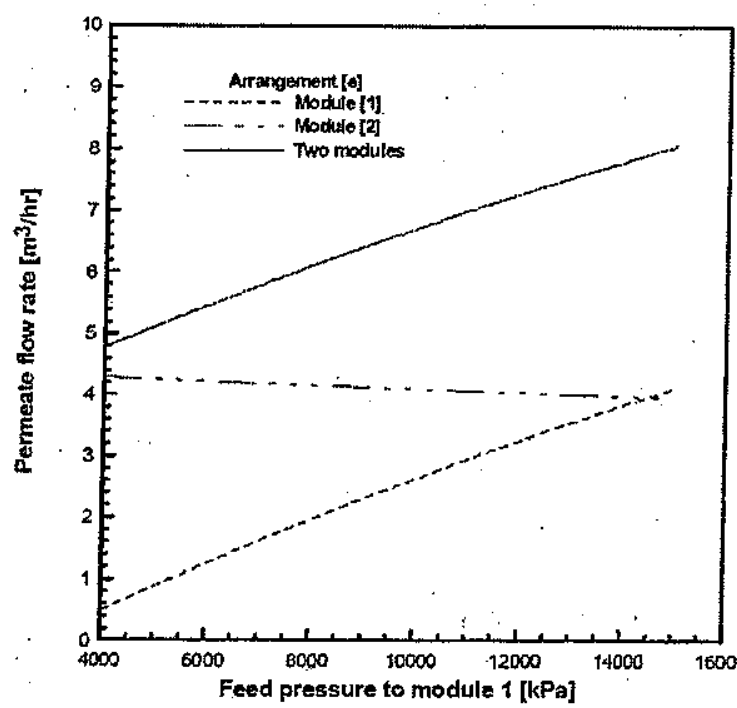

Fig. 7 Variation of Permeate Flow Rate with Feed Pressure

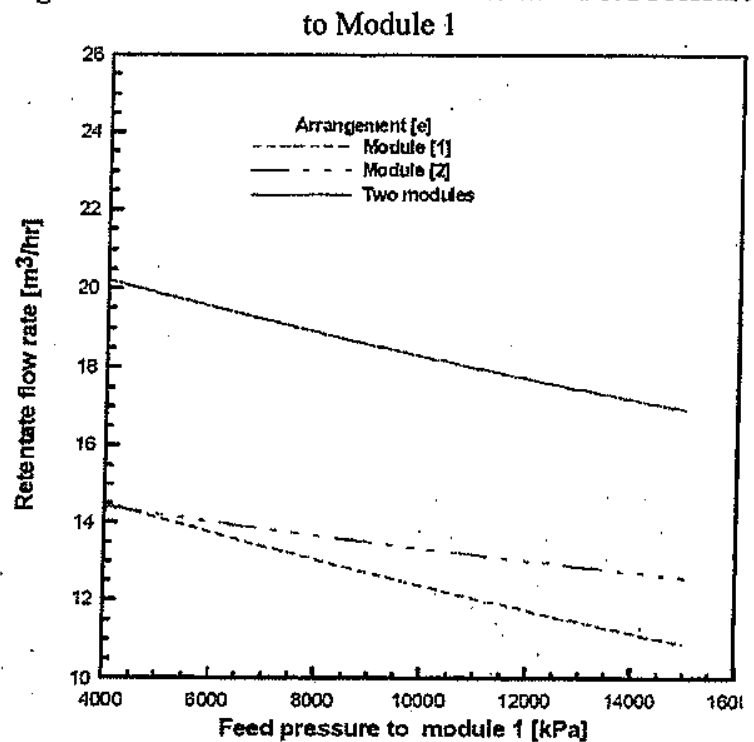

Fig. 8 Variation of Retentate Flow Rate with Feed Pressure

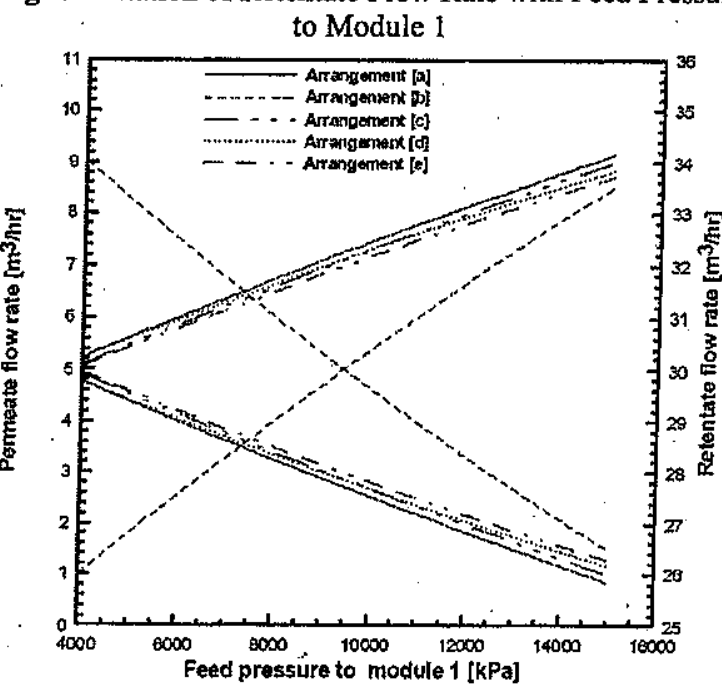

Fig. 9 Variation of Permeate and Retentate Flow Rate with Feed Pressure to Module 1 for Retentate Re-processing Arrangements 


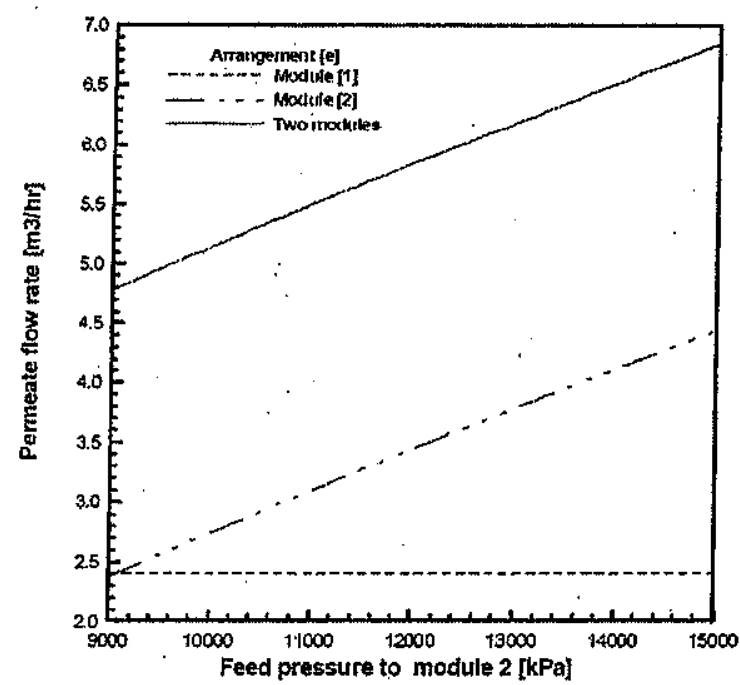

Fig. 10 Variation of Permeate Flow Rate with Feed Pressure to Module 2

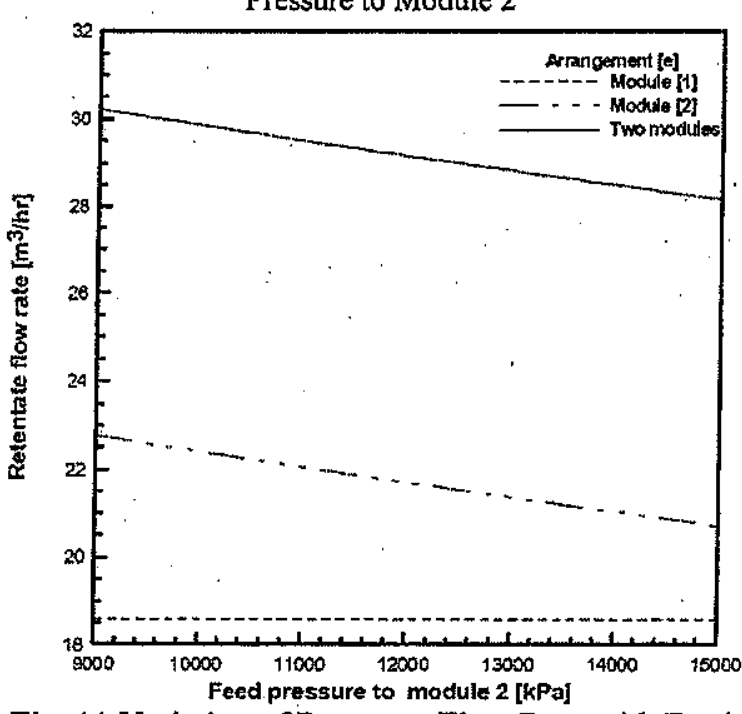

Fig. 11 Variation of Retentate Flow Rate with Feed

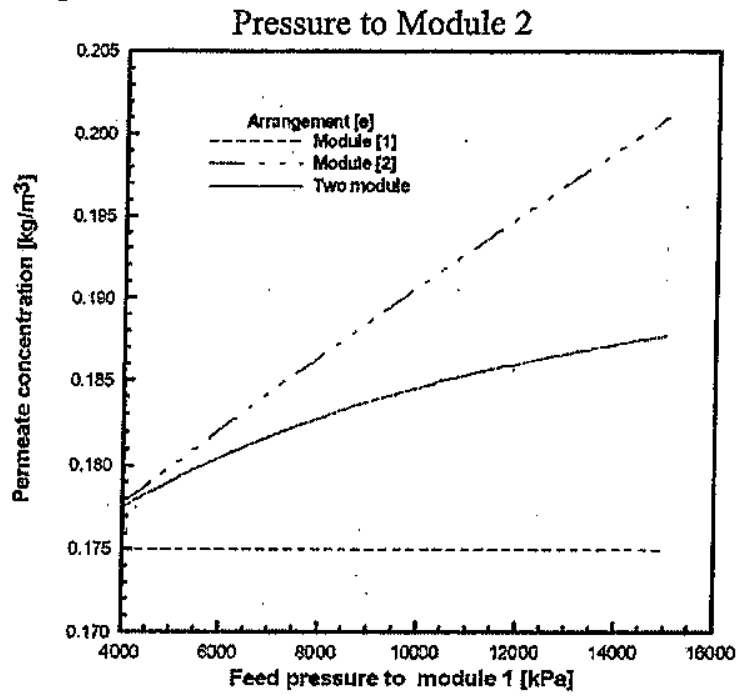

Fig. 12 Variation of Permeate Concentration with Feed Pressure to Module 1

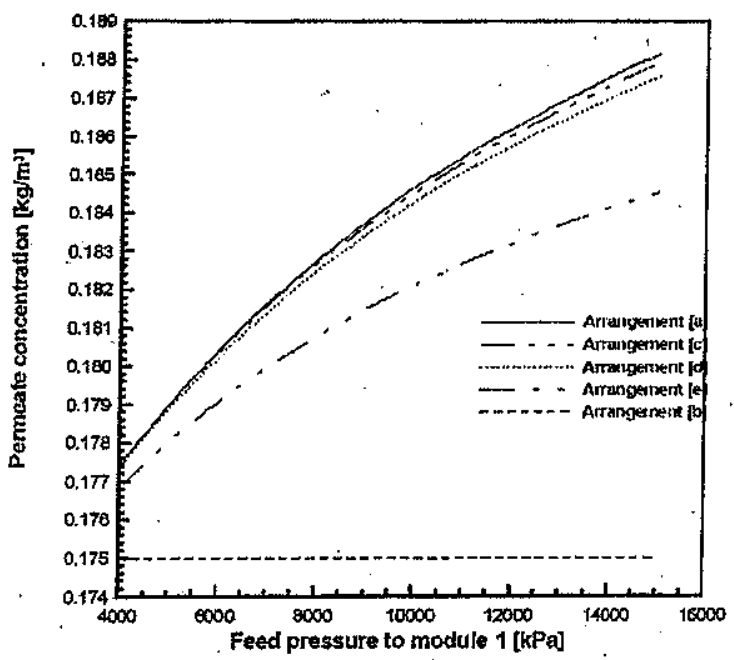

Fig. 13 Variation of Permeate Concentration with Feed Pressure to Module 1 for Retentate Re-

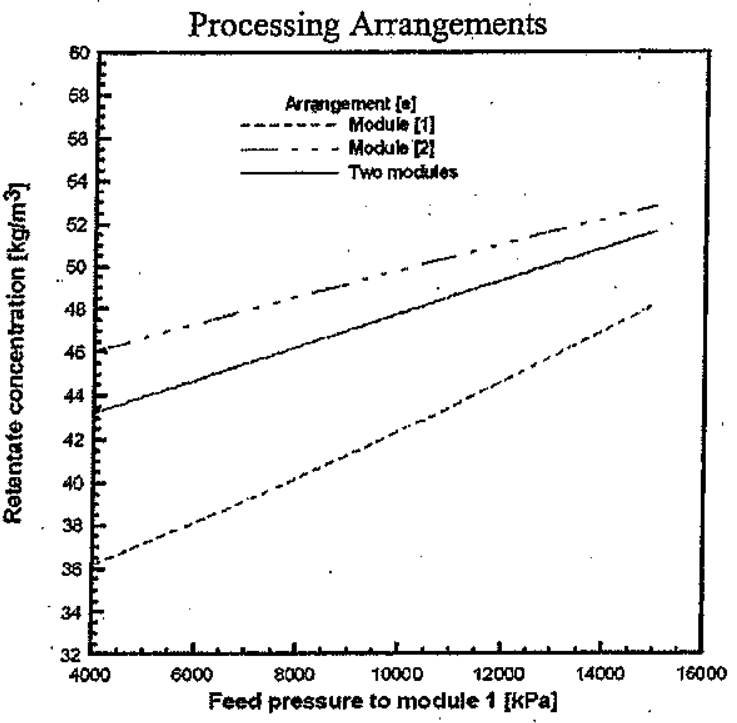

Fig. 14 Variation of Retentate Concentration with

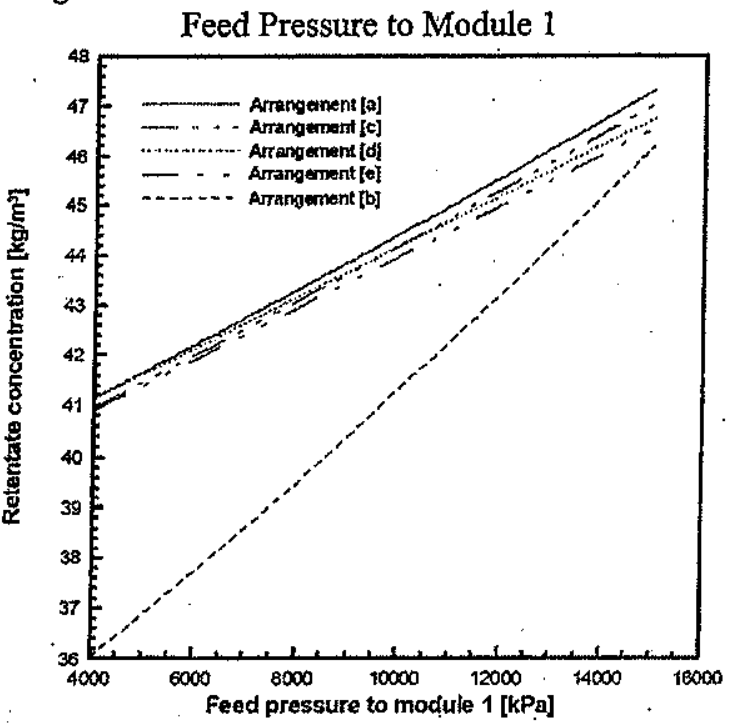

Fig. 15 Variation of Retentate Concentration with Feed Pressure to Module 1 for Retentate Reprocessing Arrangements 
H. Kotb, E. H. Amer and K. A. Ibrahim, "Parametric Study of Retentate Re-Processing RO Desalination Units"

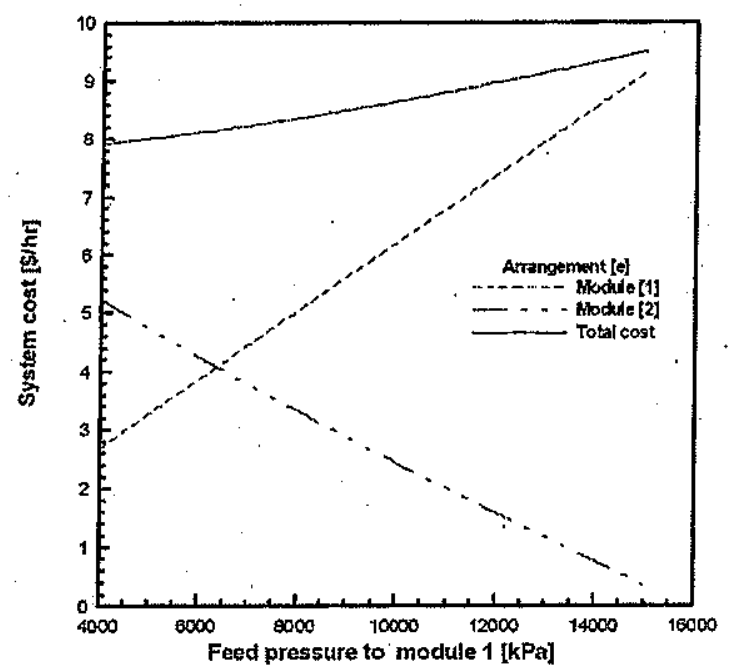

Fig. 16 Variation of System. Cost with Feed Pressure to Module 1

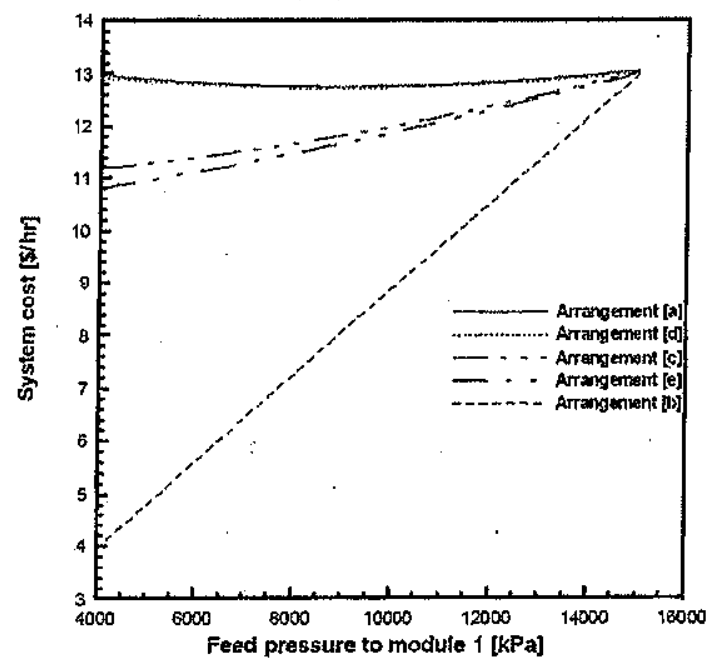

Fig. 17 Variation of System Cost with Feed Pressure to Module 1 for Retentate Re-processing Arrangements

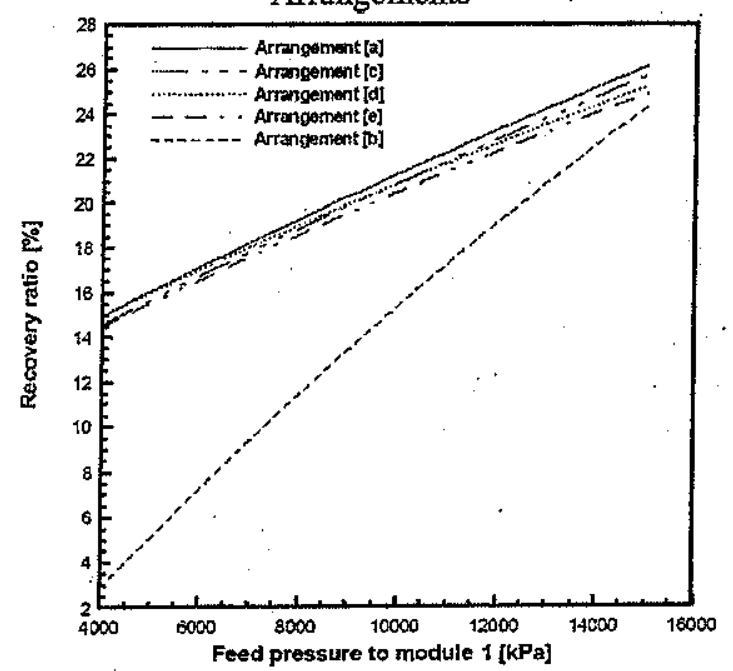

Fig. 18 Variation of Recovery Ratio with Feed Pressure to Module 1 for Retentate Re-processing Arrangements

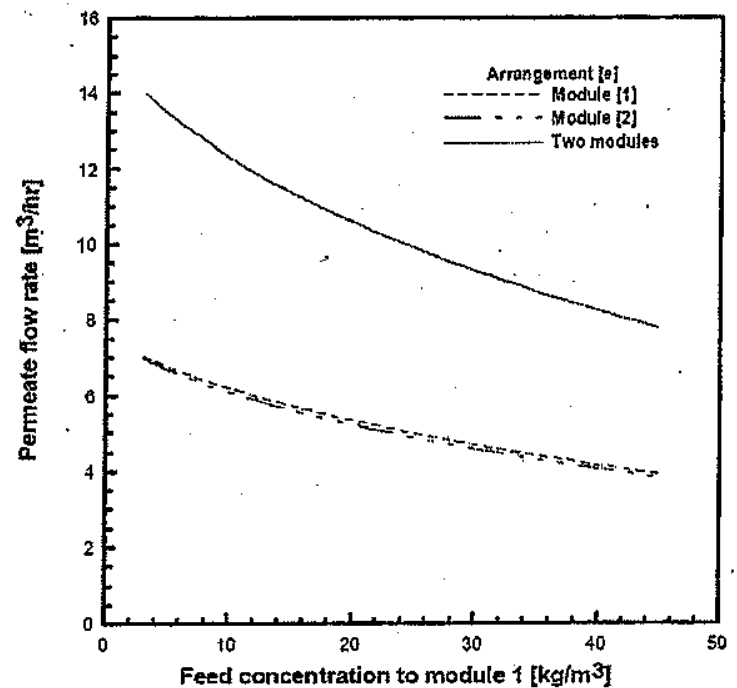

Fig. 19 Variation of Permeate Flow Rate with Feed Concentration to Module 1

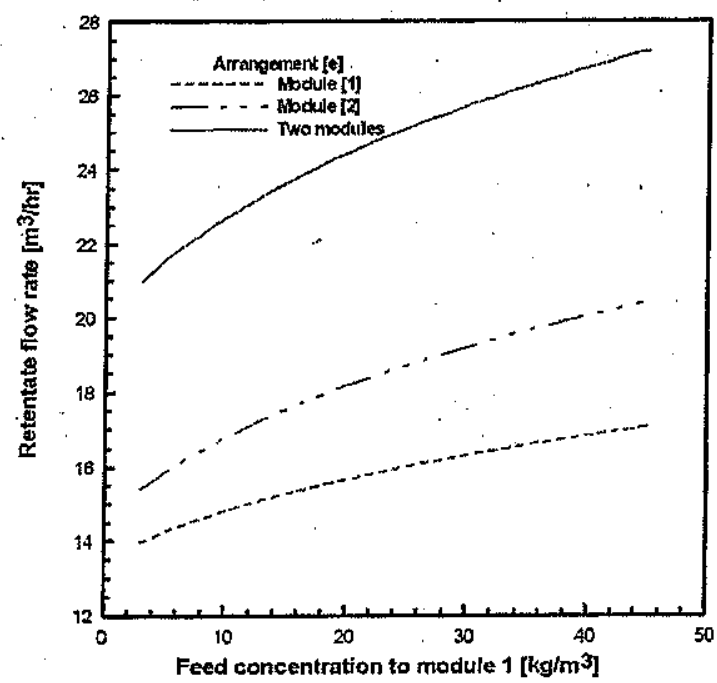

Fig. 20 Variation of Retentate Flow Rate with Feed Concentration to Module1

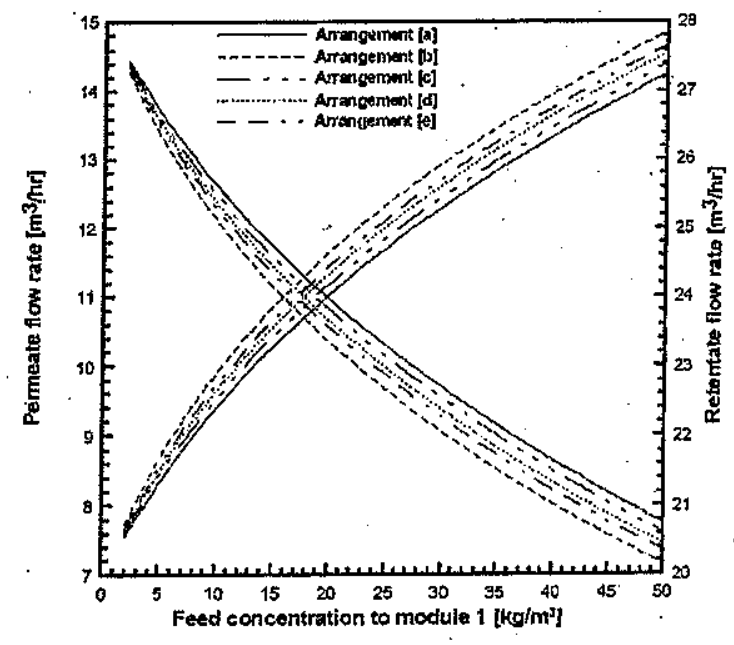

Fig. 21 Variation of Permeate and Retentate Flow Rate with Feed Concentration to Module 1 for Retentate Re-processing Arrangements 


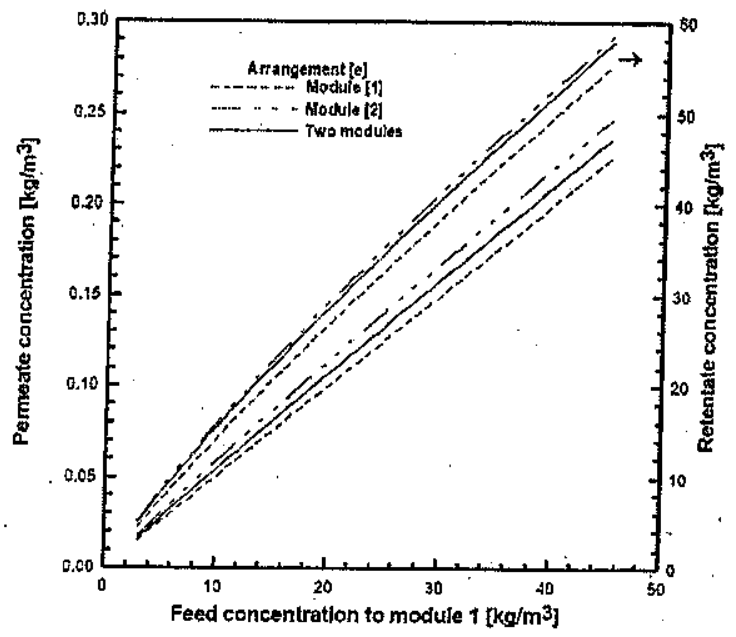

Fig. 22 Variation of Permeate and Retentate

Concentration with Feed Concentration to Module 1

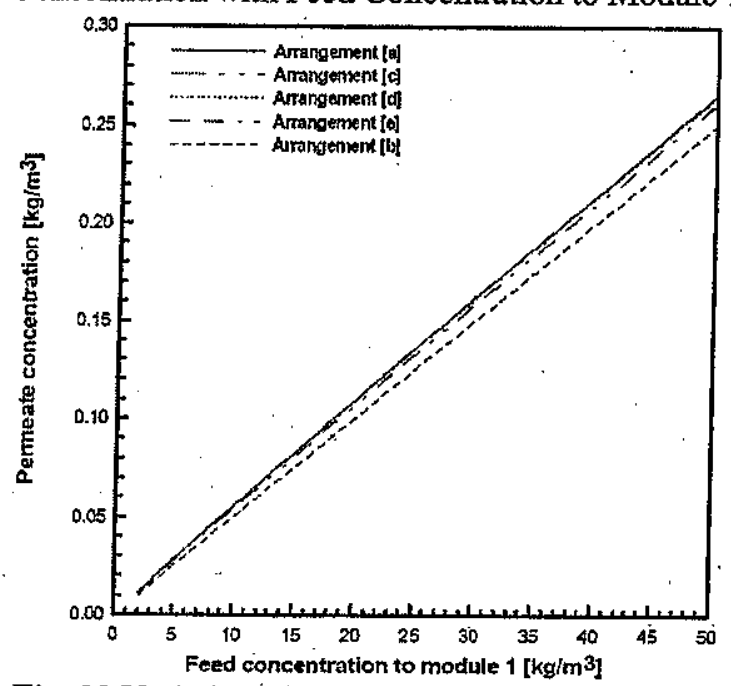

Fig. 23 Variation of Permeate Concentration with Feed Concentration to Module 1 for Retentate Re-

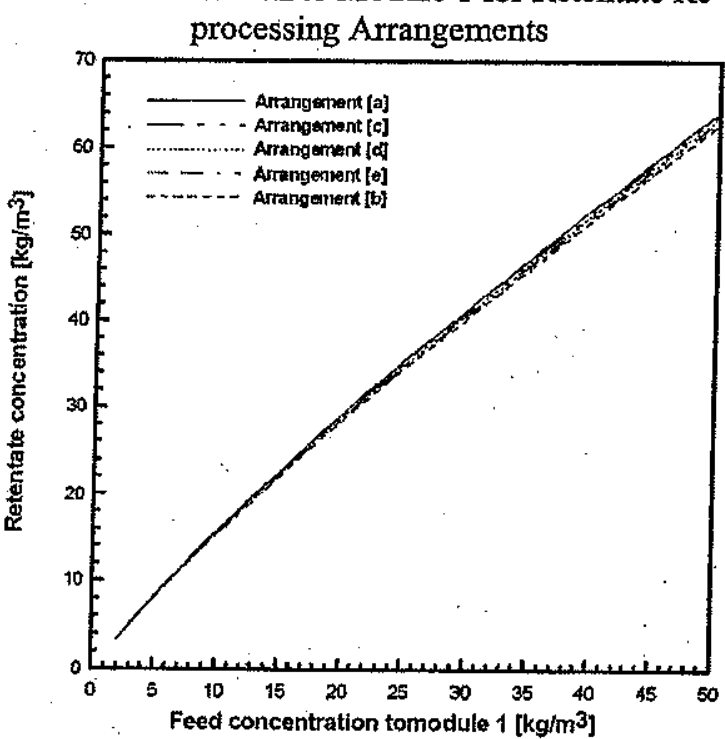

Fig. 24 Variation of Retentate Concentration with Feed Concentration to Module 1 for Retentate $\mathrm{Re}$ processing Arrangements

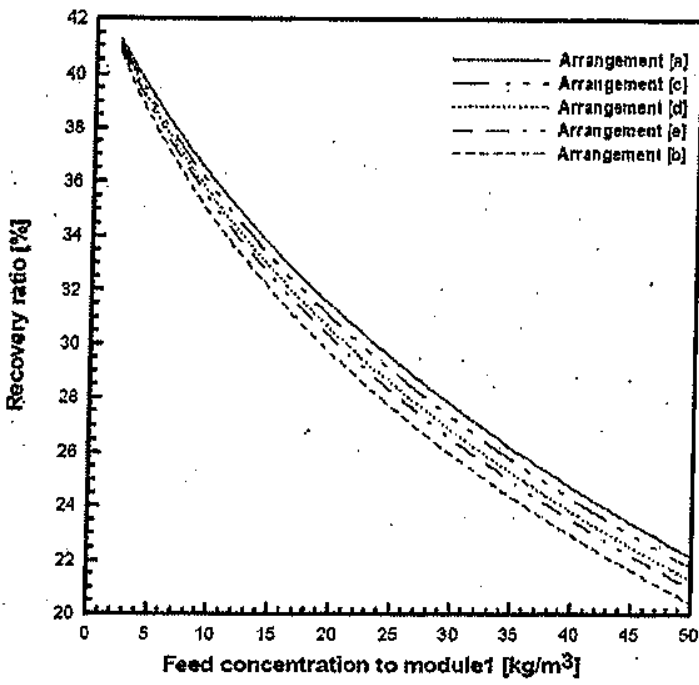

Fig. 25 Variation of Recovery Ratio with Feed Concentration to Module 1 for Retentate Reprocessing Arrangements

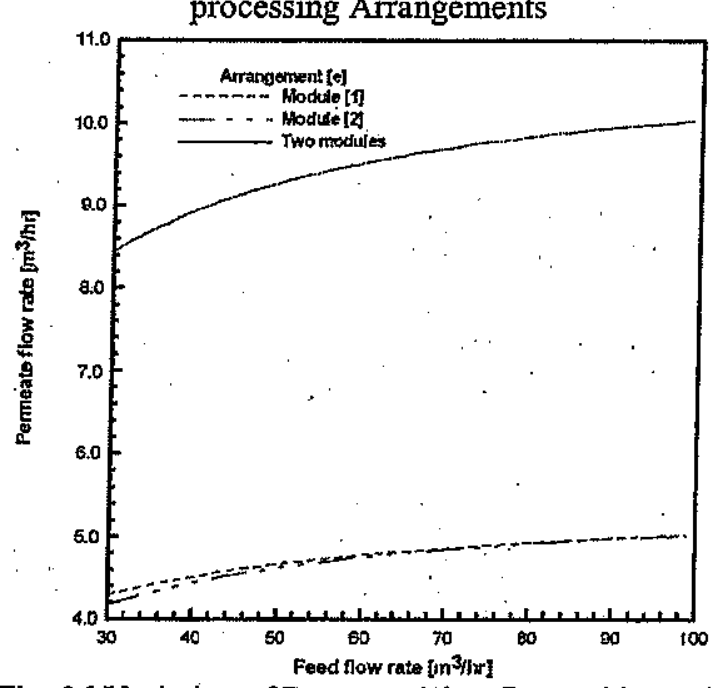

Fig. 26 Variation of Permeate Flow Rate with Feed Flow Rate

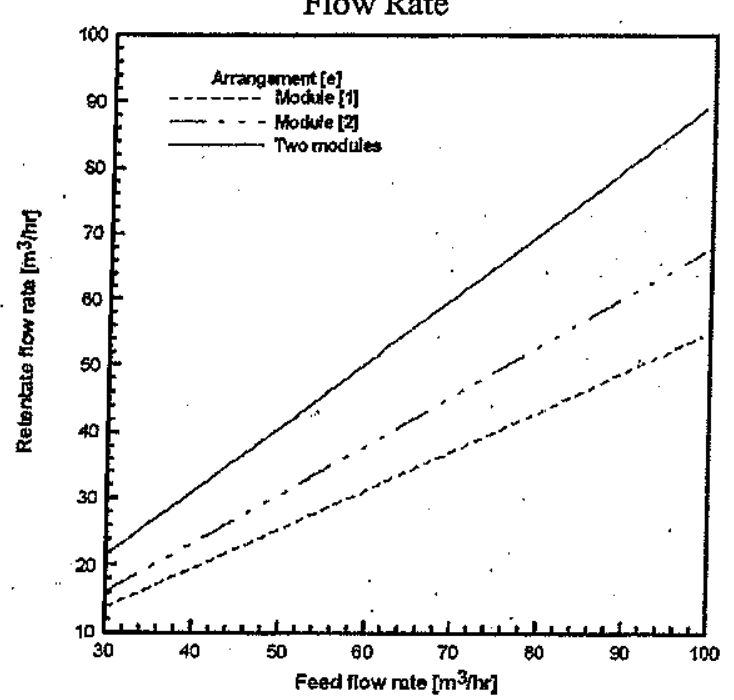

Fig. 27 Variation of Retentate Flow Rate with Feed Flow Rate. 


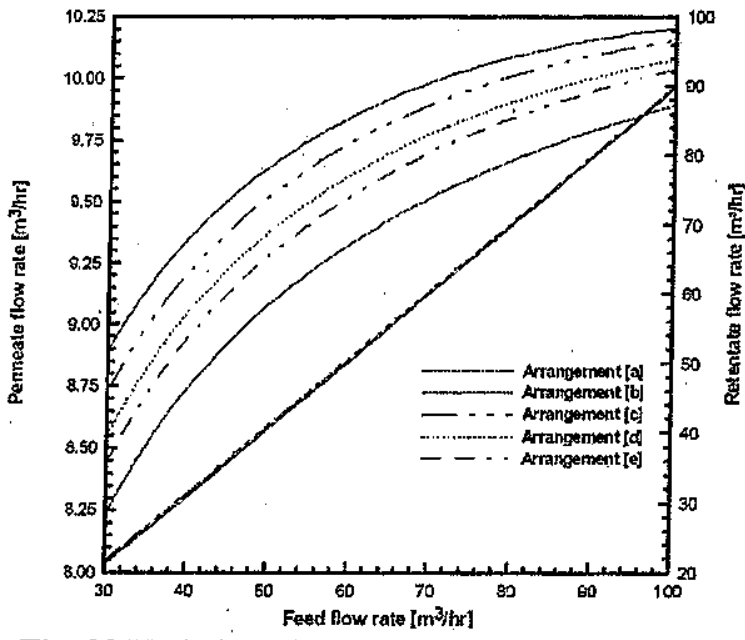

Fig. 28 Variation of Permeate and Retentate Flow Rate with Feed Flow Rate for Retentate Reprocessing Arrangements

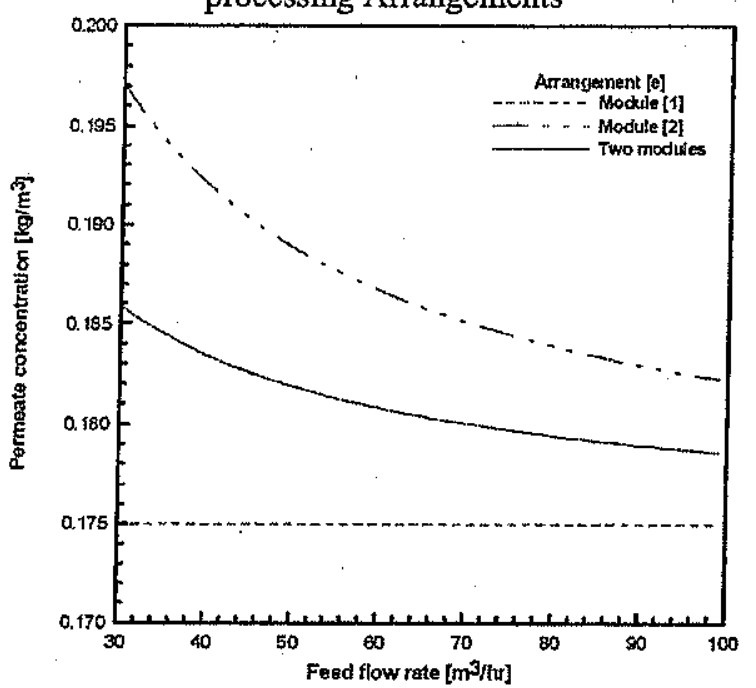

Fig. 29 Variation of Permeate Concentration with

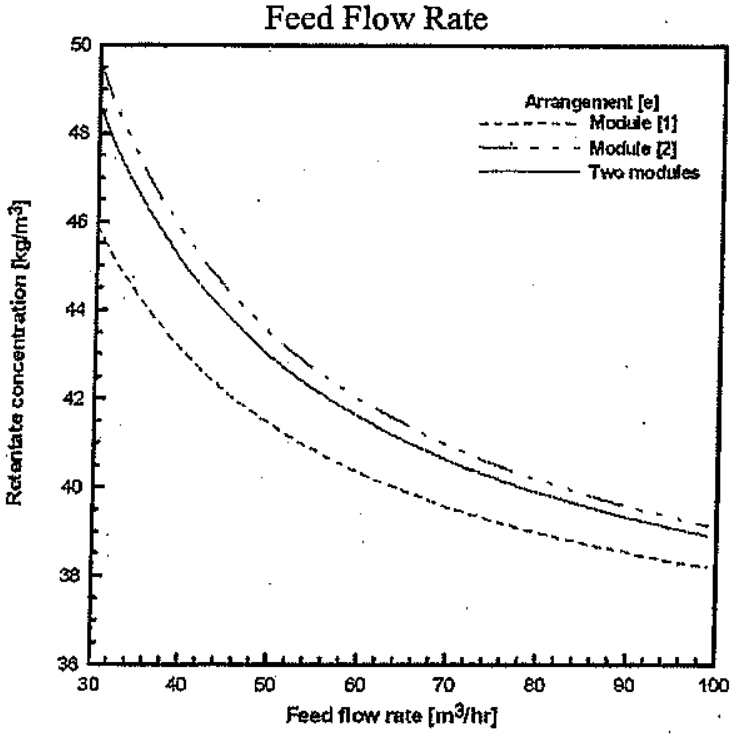

Fig. 30 Variation of Retentate Concentration with Feed Flow Rate.

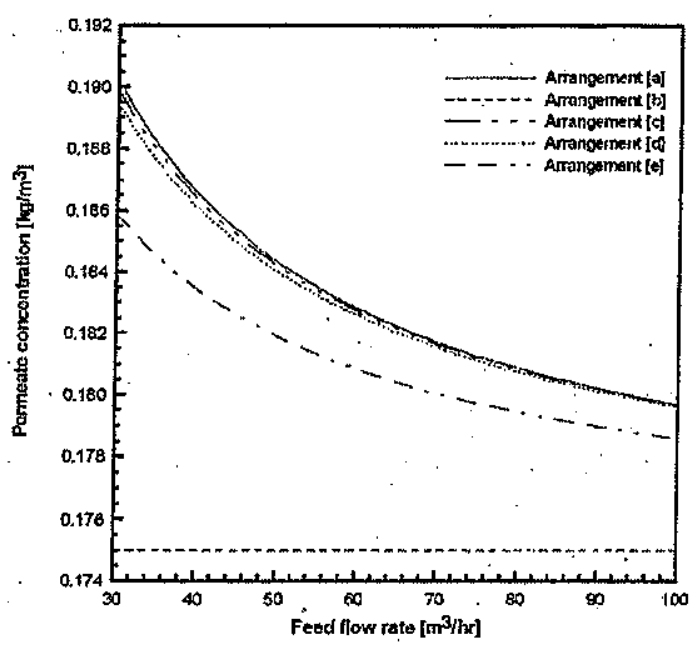

Fig. 31 Variation of Permeate Concentration with Feed Flow Rate for Retentate Re-processing Arrangements

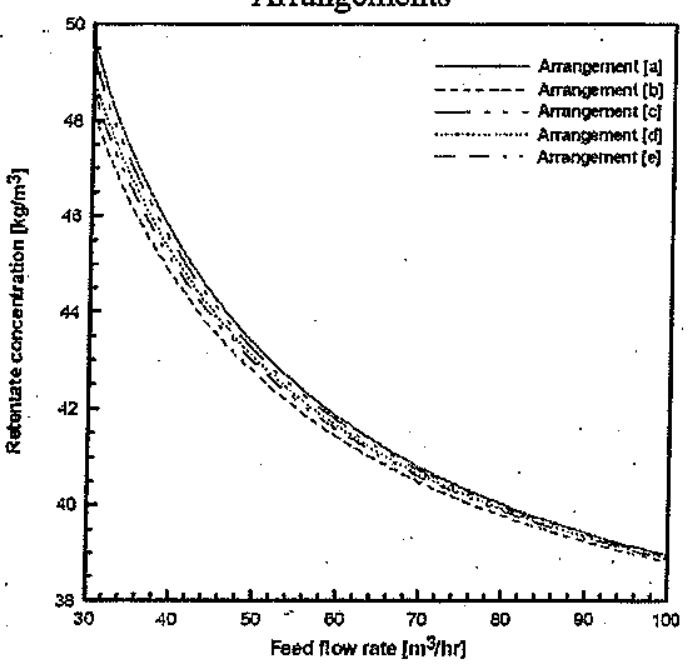

Fig. 32 Variation of Retentate Concentration with Feed Flow Rate for Retentate Re-processing Arrangements

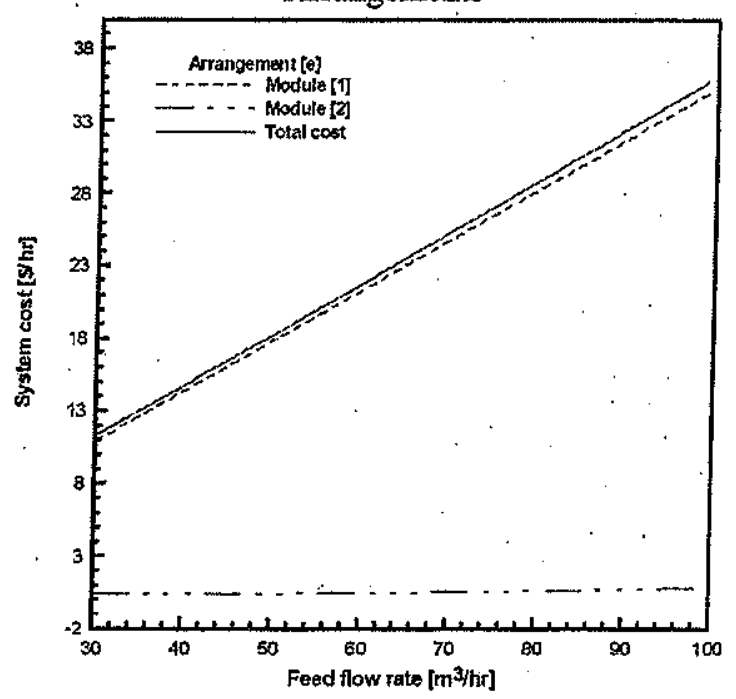

Fig. 33 Variation of System Cost with Feed Flow Rate 


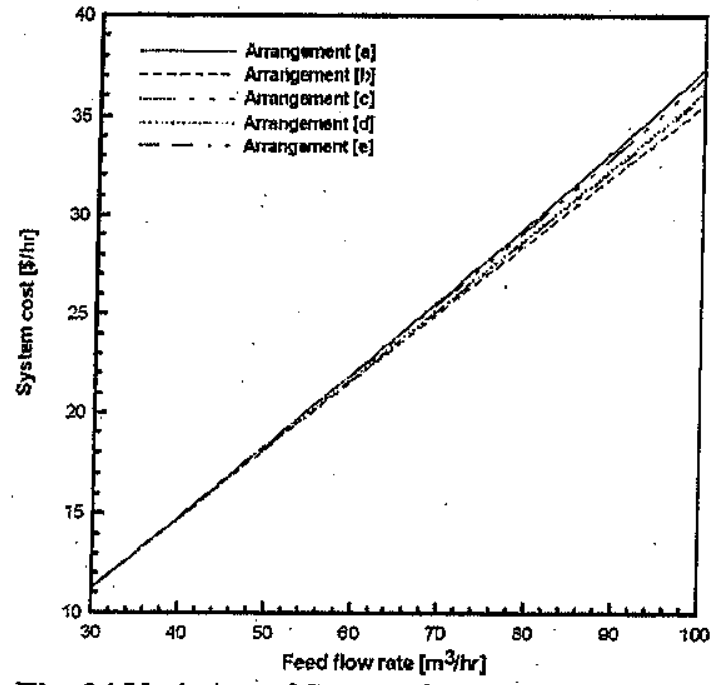

Fig. 34 Variation of System Cost with Feed Flow Rate for Retentate Re-processing Arrangements

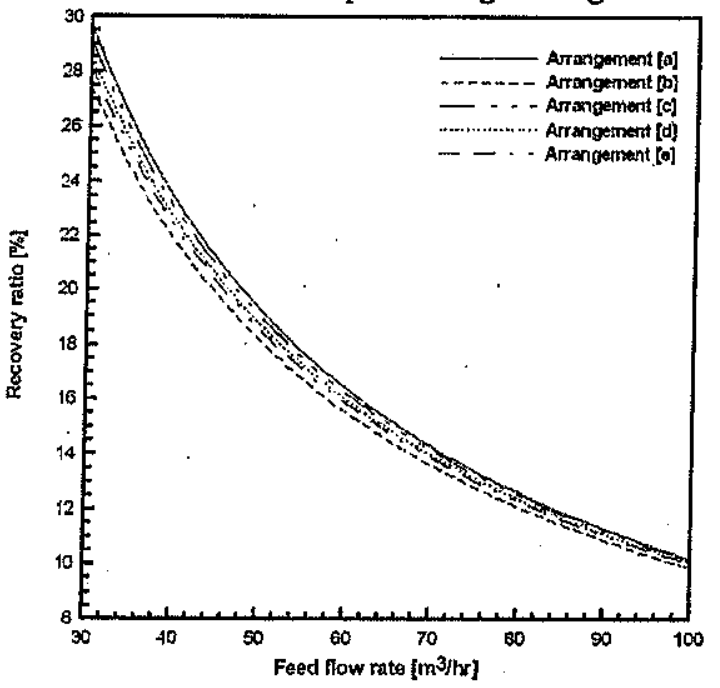

Fig. 35 Variation of Recovery Ratio with Feed Flow Rate for Retentate Re-processing Arrangements

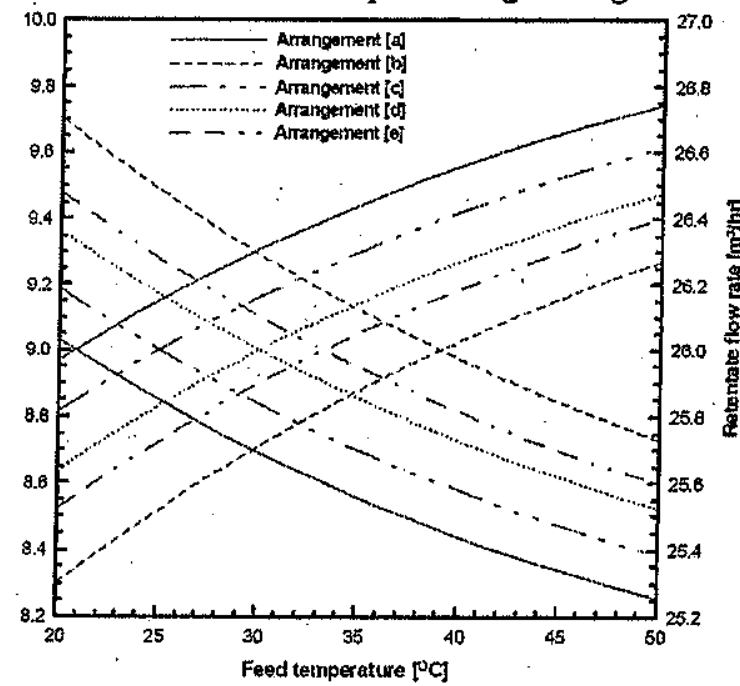

Fig. 36 Variation of Permeate and Retentate Flow Rate with Feed Temperature for Retentate Reprocessing Arrangements

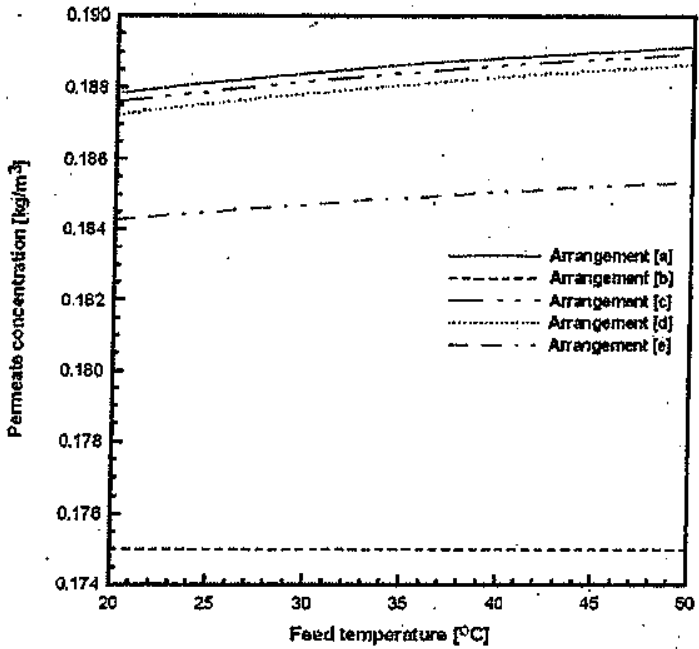

Fig. 37 Variation of Permeate Concentration with Feed Temperature for Retentate Re-processing Arrangements

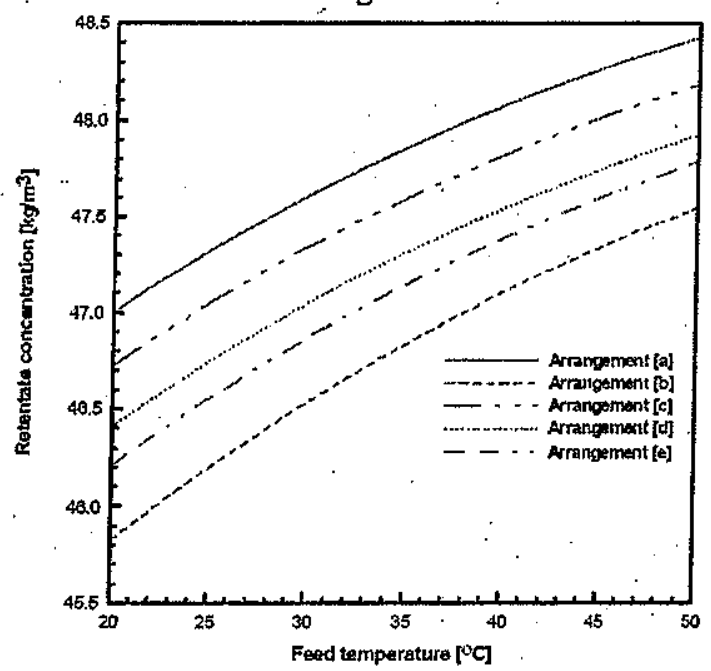

Fig. 38 Variation of Permeate Concentration with .Feed Temperature for Retentate Re-processing Arrangements

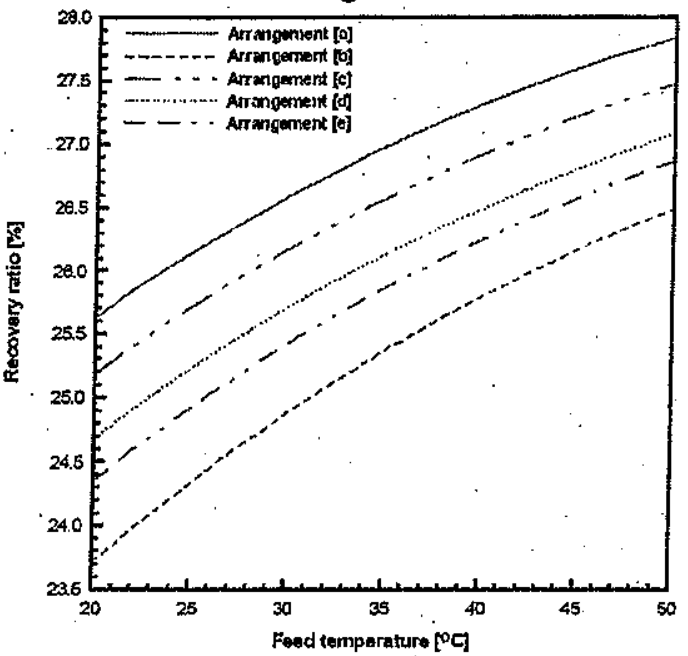

Fig. 39 Variation of Recovery Ratio with Feed Temperature for Retentate Re-processing Arrangements 


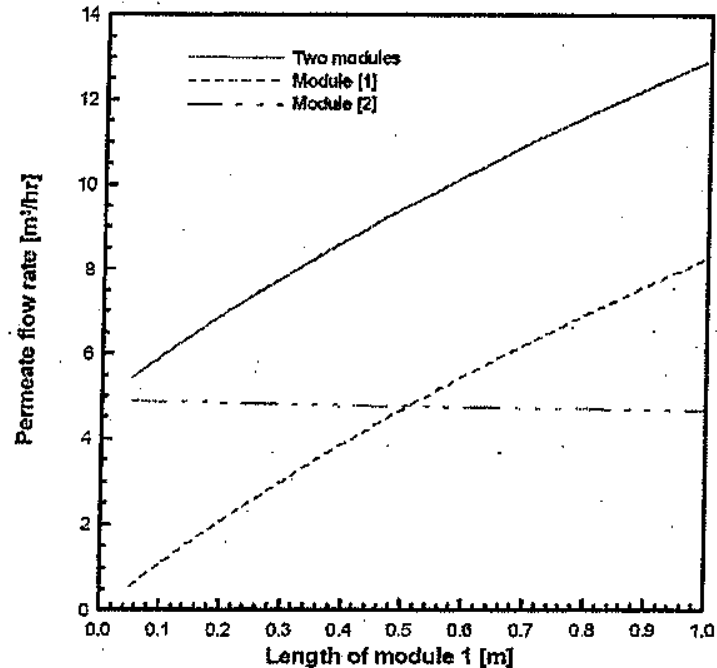

Fig. 40 Variation of Permeate Flow Rate with Length of Module 1

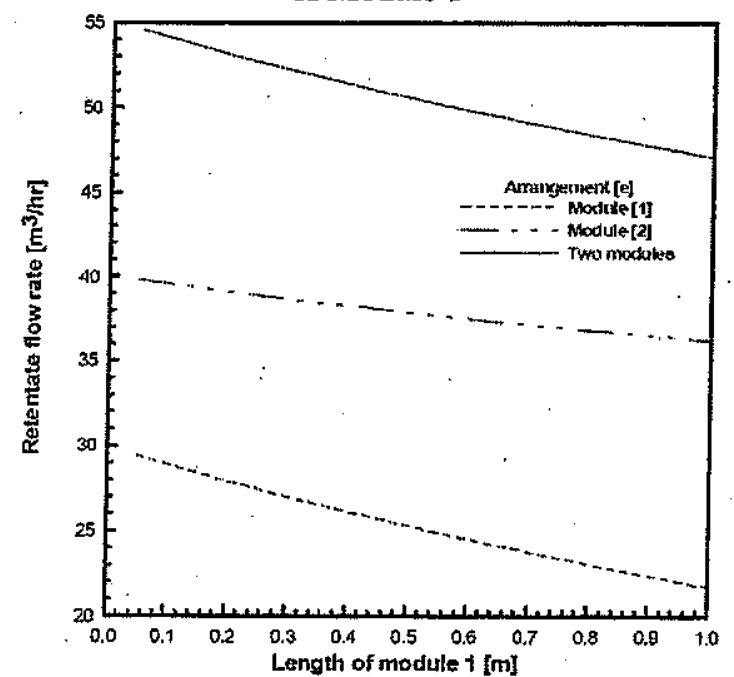

Fig. 41 Variation of Retentate Flow Rate with Length of Module 1

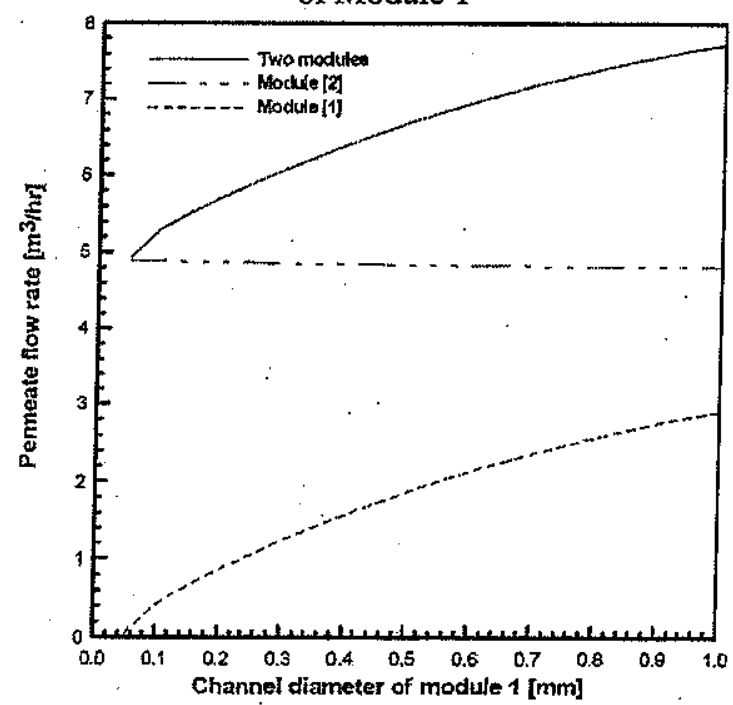

Fig. 42 Variation of Permeate Flow Rate with Channel Diameter of Module 1

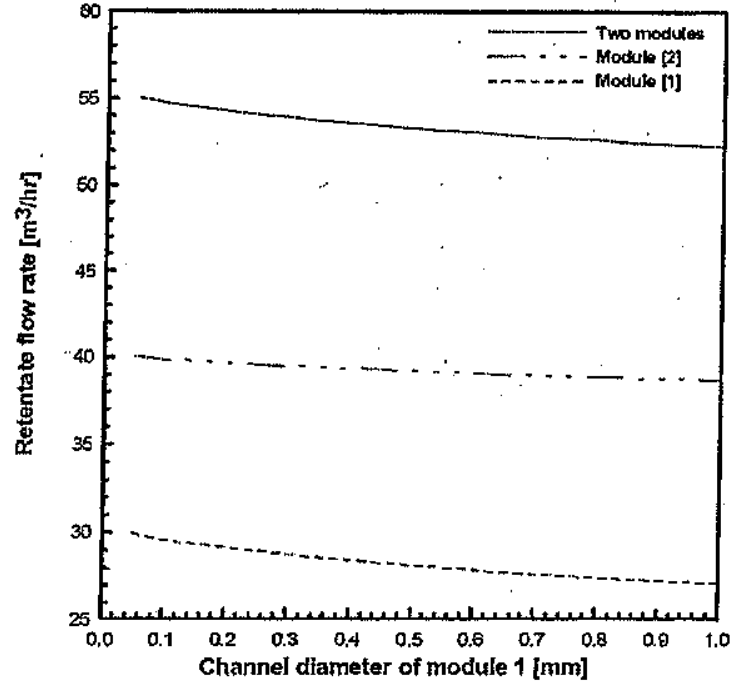

Fig. 43 Variation of Retentate Flow Rate with Channel Diameter of Module 1

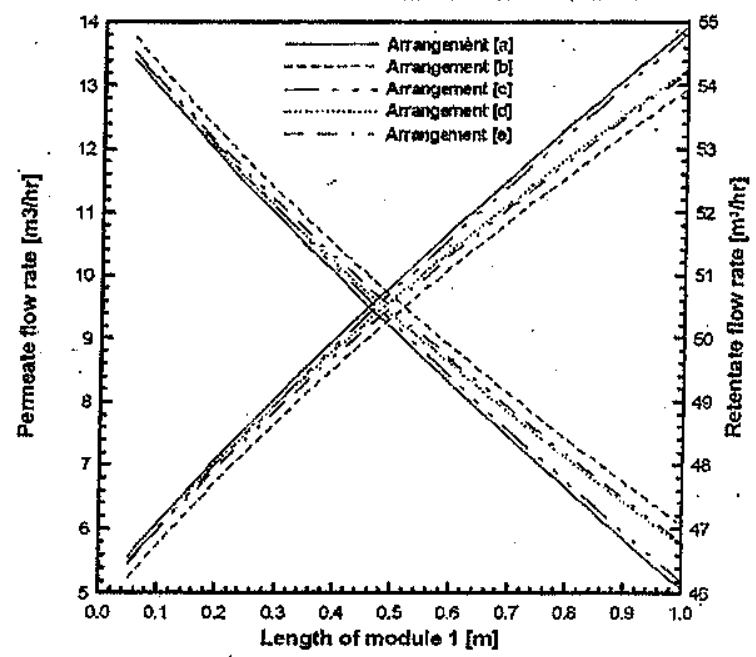

Fig. 44 Variation of Permeate and Retentate Flow Rate with First Module Length for Retentate Re-

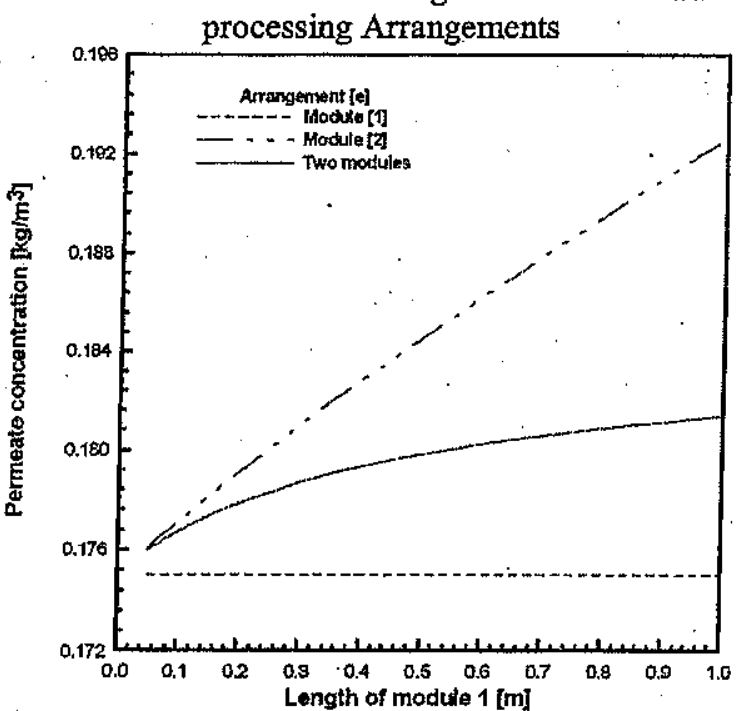

Fig. 45 Variation of Permeate Concentration with Length of Module 1 


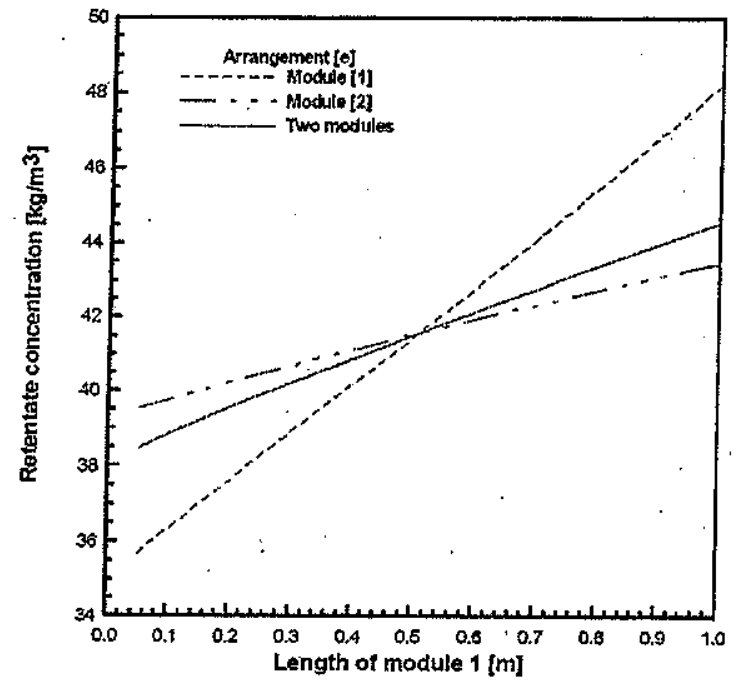

Fig. 46 Variation of Retentate Concentration with

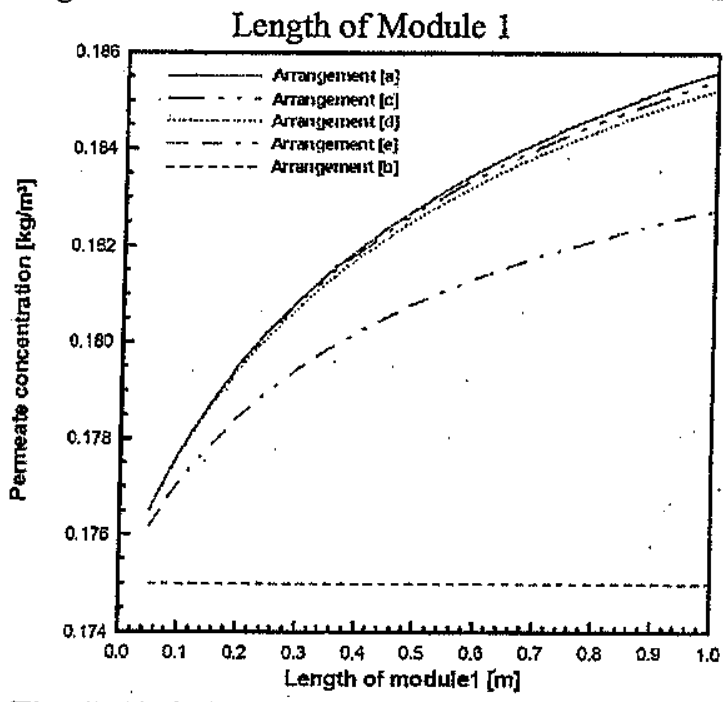

Fig. 47 Variation of Permeate Concentration with Length of Module 1 for Retentate Re-processing Arrangements

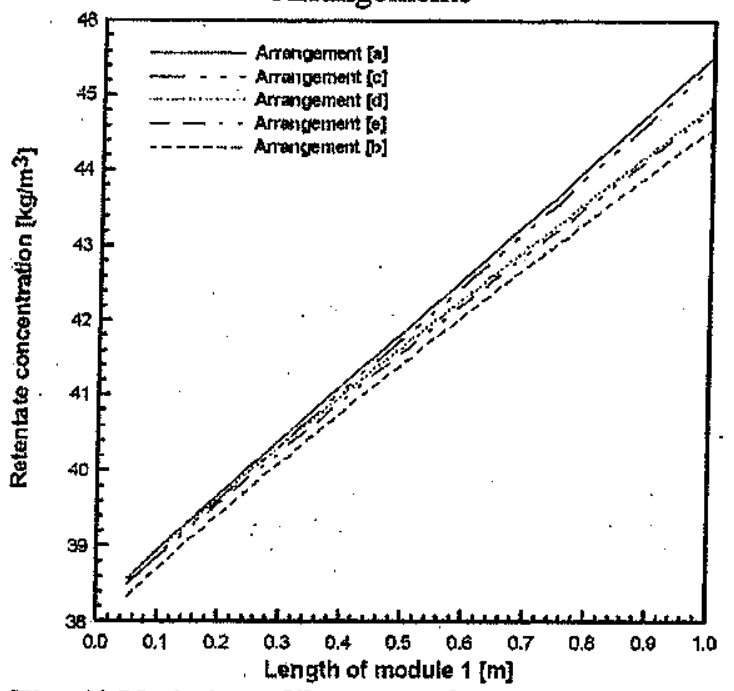

Fig. 48 Variation of Retentate Concentration with Length of Module 1 for Retentate Re-processing Arrangements

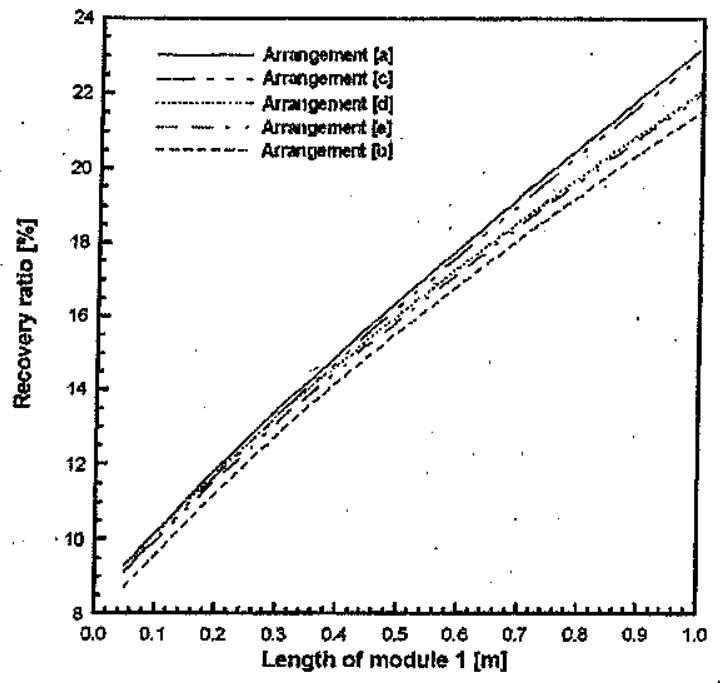

Fig. 49 Variation of Recovery Ratio with Length of Module 1 for Retentate Re-processing Arrangements

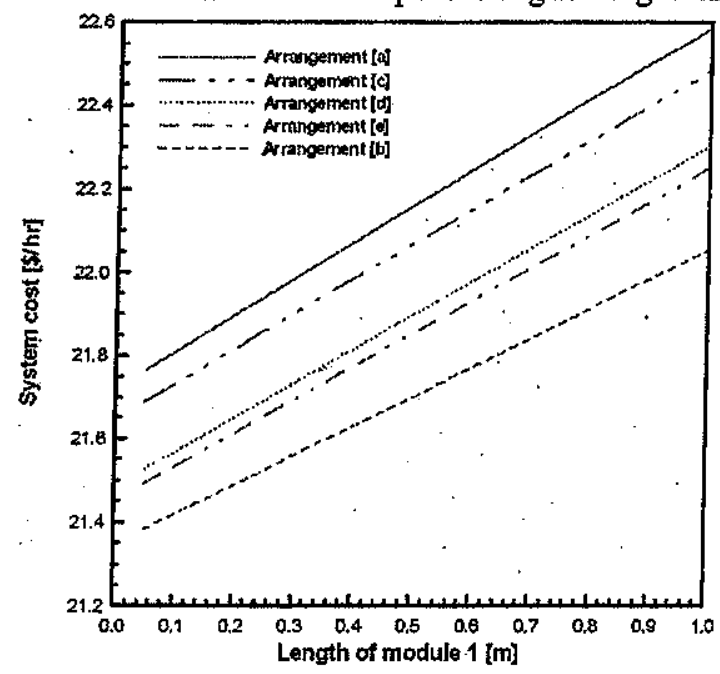

Fig. 50 Variation of System Cost with Length of Module 1 for Retentate Re-processing Arrangements

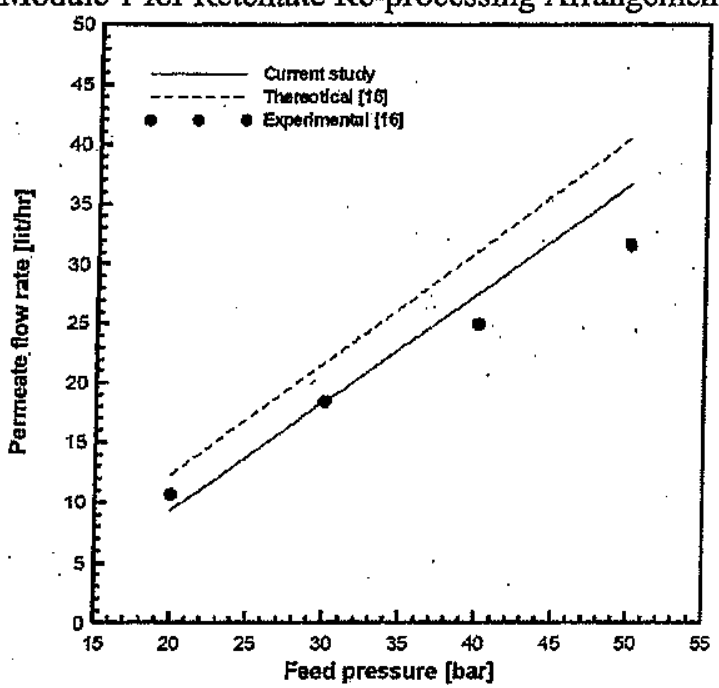

Fig. 51 Variation of Permeate Flow Rate with Feed Pressure to Module 1 
H. Kotb, E. H. Amer and K. A. Ibrahim, "Parametric Study of Retentate Re-Processing RO Desalination Units"

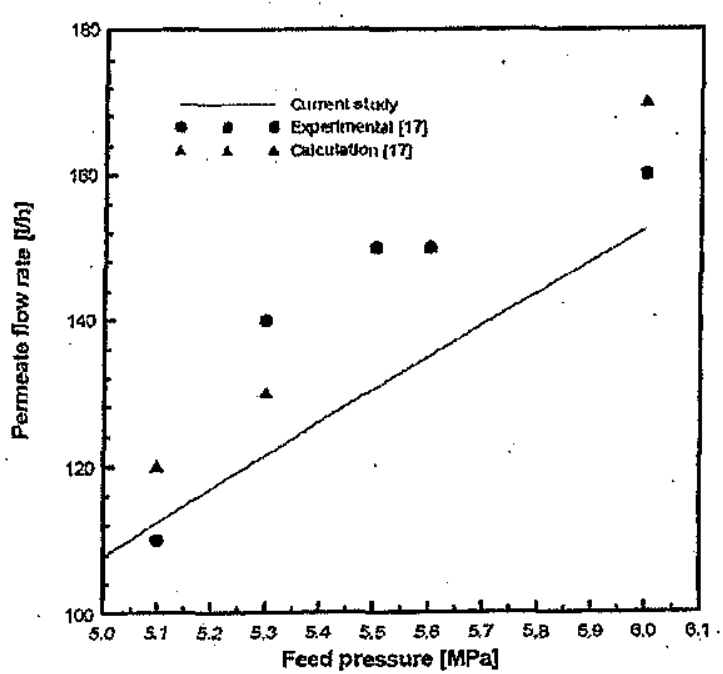

Fig. 52 Variation of Permeate Flow Rate with Feed Pressure to Module 1

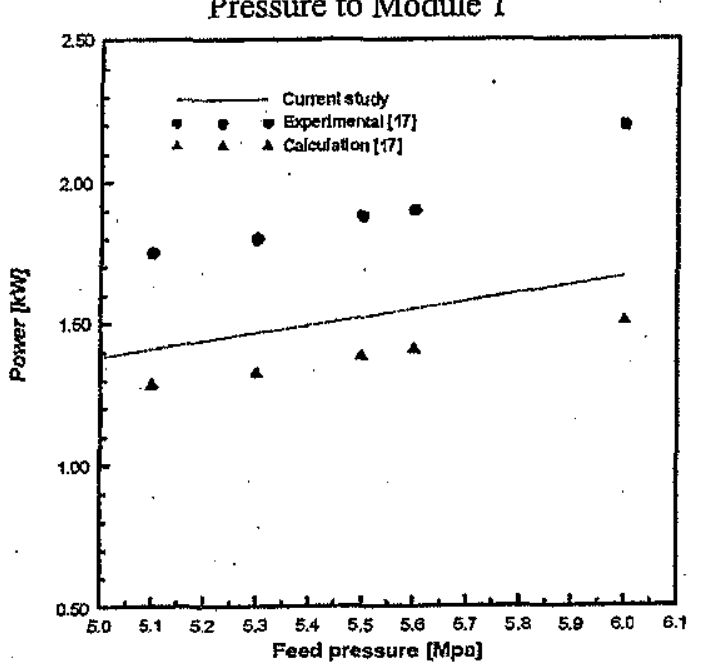

Fìg. 53 Variation of Power Consumption with Feed Pressure to Module 1

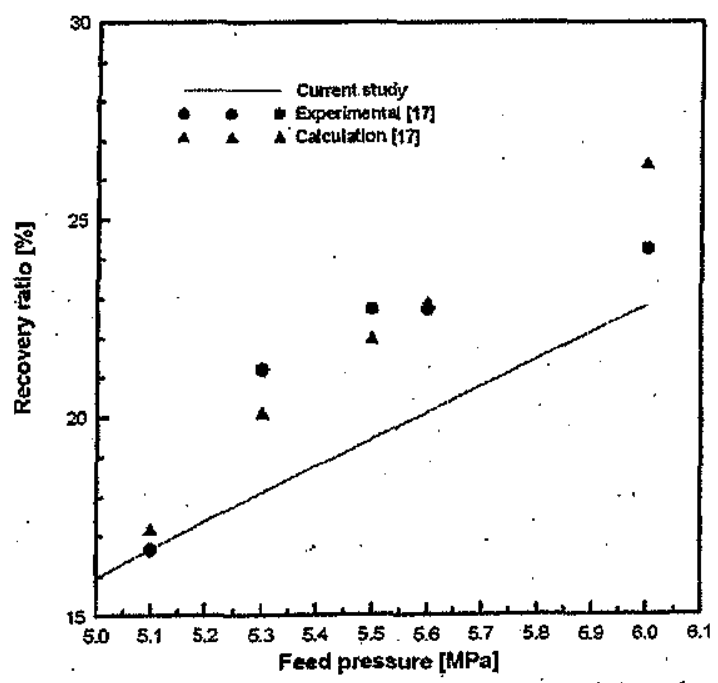

Fig. 54 Variation of Recovery Ratio with Feed Pressure to Module 1

Table 1 Various Two Module RO Arrangements and their Split Ratios

\begin{tabular}{|c|c|c|c|c|}
\hline Arrangement & Figure & $\mathbf{X}_{\mathbf{r}}$ & $\mathbf{X}_{\mathbf{r}}$ & $\mathbf{x}_{1}$ \\
\hline Series, Retentate Re-processing & $(1-a)$ & 0 & 1 & 0 \\
\hline Parallel Arrangement & $(1-b)$ & $0<\mathrm{X}_{\mathrm{f}}<1$ & 0 & 0 \\
\hline $\begin{array}{l}\text { Series with Retentate Bypass, Retentate } \\
\text { Re-processing }\end{array}$ & $(1-c)$ & 0 & $0<\mathrm{X}_{\mathrm{r}}<1$ & 0 \\
\hline $\begin{array}{l}\text { Series with Feed bypass, Retentate Re- } \\
\text { processing }\end{array}$ & $(1-d)$ & $0<\mathrm{X}_{\mathrm{f}}<1$ & $X_{1}=1$ & 0 \\
\hline $\begin{array}{l}\text { Series with Feed and Retentate Bypass, } \\
\text { Retentate Re-processing }\end{array}$ & $(1-e)$ & $0<X_{\mathrm{f}}<1$ & $0<\mathrm{X}_{\mathrm{r}}<1$ & 0 \\
\hline Series, Permeate Re-processing & $(1-\hat{f})$ & 0 & 0 & $X_{p}=1$ \\
\hline $\begin{array}{l}\text { Series with Feed Bypass, Permeate } \mathrm{Re} \text { - } \\
\text { processing }\end{array}$ & $(1-g)$ & $0<\mathrm{X}_{\mathrm{f}}<1$ & 0 & $X_{p}=1$ \\
\hline $\begin{array}{l}\text { Series with Permeate Bypass, Permeate } \\
\text { Re-processing }\end{array}$ & $(1-b)$ & 0 & 0 & $0<\mathrm{X}_{\mathrm{p}}<1$ \\
\hline Series with Feed and Permeate By pass & $(1-i)$ & $0<\mathrm{X}_{\mathrm{f}}<1$ & 0 & $0<\mathrm{X}_{\mathrm{p}}<\mathrm{l}$ \\
\hline
\end{tabular}

